\title{
Human organ chip-enabled pipeline to rapidly repurpose therapeutics
} Jiang $^{3}$, Rasmus Moller ${ }^{4}$, Daisy Hoagland ${ }^{4}$, Kohei Oishi ${ }^{4}$, Shu Horiuchi ${ }^{4}$, Skyler Uhl $^{4}$, Daniel Blanco-Melo ${ }^{4}$, Randy A. Albrecht ${ }^{4,5}$, Wen-Chun Liư ${ }^{4,5}$, Tristan Jordan ${ }^{4}$, Benjamin E. Nilsson-Payant ${ }^{4}$, James Logue ${ }^{6}$, Robert Haupt ${ }^{6}$, Marisa McGrath ${ }^{6}$, Stuart Weston ${ }^{6}$, Atiq Nurani ${ }^{1}$, Seong Min Kim¹, Danni Y. Zhu1, Kambez H. Benam ${ }^{1,+}$, Girija Goyal' Sarah E. Gilpin ${ }^{1}$, Rachelle Prantil-Baun ${ }^{1}$, Rani K. Powers ${ }^{1}$, Kenneth Carlson ${ }^{1}$, Matthew Frieman ${ }^{6}$, Benjamin R. tenOever ${ }^{*}$, and Donald E. Ingber ${ }^{1-3^{*}}$

${ }^{1}$ Wyss Institute for Biologically Inspired Engineering, Harvard University, Boston, MA 02115, USA.

${ }^{2}$ Harvard John A. Paulson School of Engineering and Applied Sciences, Cambridge, MA 02139, USA.

${ }^{3}$ Vascular Biology Program and Department of Surgery, Boston Children's Hospital and Harvard Medical School, Boston, MA 02115, USA.

${ }^{4}$ Department of Microbiology, Icahn School of Medicine at Mount Sinai, New York, NY, USA.

${ }^{5}$ Global Health and Emerging Pathogens Institute, Icahn School of Medicine at Mount Sinai, New York, NY, USA.

${ }^{6}$ Department of Microbiology and Immunology, University of Maryland School of Medicine, Baltimore, MD 21201, USA

+Current address: Division of Pulmonary Sciences and Critical Care Medicine, Departments of Medicine \& Bioengineering, U. of Colorado, Aurora, CO, USA.

\#Co-first Authors

${ }^{*}$ Co-corresponding Authors:

Donald E. Ingber, MD, PhD, Wyss Institute for Biologically Inspired Engineering at Harvard University, CLSB5, 3 Blackfan Circle, Boston MA 02115 (ph: 617-4327044, fax: 617-432-7828; email: don.ingber@wyss.harvard.edu

Benjamin R. tenOever, PhD, Icahn School of Medicine at Mount Sinai, Department of Microbiology, New York, NY 10023 (ph: 212-241-7849; email: Benjamin.tenOever@mssm.edu 
The rising threat of pandemic viruses, such as SARS-CoV-2, requires development of new preclinical discovery platforms that can more rapidly identify therapeutics that are active in vitro and also translate in vivo. Here we show that human organ-on-a-chip (Organ Chip) microfluidic culture devices lined by highly differentiated human primary lung airway epithelium and endothelium can be used to model virus entry, replication, strain-dependent virulence, host cytokine production, and recruitment of circulating immune cells in response to infection by respiratory viruses with great pandemic potential. We provide a first demonstration of drug repurposing by using oseltamivir in influenza A virusinfected organ chip cultures and show that co-administration of the approved anticoagulant drug, nafamostat, can double oseltamivir's therapeutic time window. With the emergence of the COVID-19 pandemic, the Airway Chips were used to assess the inhibitory activities of approved drugs that showed inhibition in traditional cell culture assays only to find that most failed when tested in the Organ Chip platform. When administered in human Airway Chips under flow at a clinically relevant dose, one drug - amodiaquine - significantly inhibited infection by a pseudotyped SARS-CoV-2 virus. Proof of concept was provided by showing that amodiaquine and its active metabolite (desethylamodiaquine) also significantly reduce viral load in both direct infection and animal-to-animal transmission models of native SARS-CoV-2 infection in hamsters. These data highlight the value of Organ Chip technology as a more stringent and physiologically relevant platform for drug repurposing, and suggest that amodiaquine should be considered for future clinical testing. 


\section{Confidential}

The increasing incidence of potential pandemic viruses, such as influenza A virus, Middle East respiratory syndrome coronavirus (MERS-CoV), Severe acute respiratory virus (SARS-CoV), and now SARS-CoV-2, requires development of new preclinical approaches that can accelerate development of effective therapeutics and prophylactics. The most rapid way to confront a pandemic challenge would be to repurpose existing drugs that are approved for other medical indications as antiviral therapeutics. While researchers and clinicians around the world are attempting to do this for the COVID-19 pandemic, current approaches have been haphazard and generally rely entirely on results of in vitro screens with cell lines. This has resulted in equivocal results regarding drug efficacies and possible toxicity risks as in the case of hydroxychloroquine and chloroquine ${ }^{1-4}$, and thus, there is a great need to address this problem in a more systematic and human-relevant way. Recognizing the potential danger of unforeseen pandemics over two years ago, the Defense Advanced Research Projects Agency (DARPA) and National Institutes of Health (NIH) funded work to explore whether human organ-on-a-chip (Organ Chip) microfluidic culture technology might be helpful in confronting potential biothreat challenges. We previously showed that Organ Chips can recapitulate human organ physiology, disease states, and therapeutic responses to clinically relevant drug exposures with high fidelity ${ }^{5-9}$. Here we show how human Lung Airway Chips may be used to model human lung responses to viral infection in vitro, and in concert with higher throughput cell-based assays and animal models, to identify existing approved drugs that have the potential to be 
81 repurposed for treating or preventing spread of viral pandemics caused by influenza $A$ 82 virus or SARS-CoV-2. Infections by respiratory viruses and antiviral drug screening assays are currently studied in vitro using cultured established cell lines, primary tissue-derived human cells, human organoids, and ex vivo human lung tissue cultures despite all having significant limitations (Supplementary Table 1) ${ }^{10-13}$. For example, established cell lines commonly demonstrate various defects in their capacity to elicit an antiviral state because normally elicited interferons cause cell cycle arrest, and so this dynamic is often selected against with continuous passaging ${ }^{14}$. Arguably even more important, cell lines and even human primary cells grown in conventional cultures do not exhibit the highly differentiated tissue structures and functions (e.g., mucociliary clearance) seen in living human organs. Explant cultures of human respiratory tract tissue circumvent this limitation, but their availability is limited and their viability can only be maintained for a short time (4-10 days $)^{12,15}$. While human lung organoids provide a

96 liquid interface $(\mathrm{ALI})$ or modeling of other physiologically relevant organ-level features of

97 lung, such as mucus layer formation, mucociliary clearance, cross-talk between

98 epithelium and endothelium, or recruitment of circulating immune cells ${ }^{10,11}$, all of which

99 play key roles in host responses to infection by respiratory viruses. Moreover, in all of

100 these culture models, drug studies are carried out under static conditions that cannot

101 predict human responses to clinically relevant, dynamic drug exposure profiles that

102 result from complex pharmacokinetics (PK) in vivo. Thus, there is an urgent need for 103 alternative preclinical in vitro models that specifically mimic human lung responses to 
104 infection by potential pandemic respiratory viruses, and because of their ability to

105 recapitulate human organ-level physiology and pathophysiology, human Lung Chips

106 offer a potential solution.

107 Influenza A virus infection and immune responses replicated in human Lung

108 Chips

109 To initially assess whether Organ Chip technology ${ }^{5-8}$ can be used to create a

110 preclinical in vitro model for therapeutics discovery, we tested it against a drug that is

111 used clinically for treatment of influenza A viral infections. The human Lung Airway Chip

112 is a microfluidic device that contains two parallel microchannels separated by an

113 extracellular matrix (ECM)-coated porous membrane (Fig. 1a) ${ }^{16}$. Primary human lung

114 airway basal stem cells are grown under an air-liquid interface (ALI) on one side of the

115 membrane in the 'airway channel', while interfaced with a primary human lung

116 endothelium grown on the opposite side of the same membrane, which is exposed to

117 continuous fluid flow of culture medium within the parallel 'vascular channel' (Fig. 1a).

118 This device supports differentiation of the lung airway basal stem cells into a

119 mucociliary, pseudostratified epithelium with proportions of airway-specific cell types

120 (ciliated cells, mucus-producing goblet cells, club cells, and basal cells) (Extended Data

121 Fig. 1a), as well as establishment of continuous ZO1-containing tight junctions and cilia

122 (Fig. 1b), permeability barrier properties, and mucus production (Extended Data Fig.

123 1b,c) similar to those observed in human airway in vivo ${ }^{17}$, as well as in prior Airway

124 Chip studies that used a membrane with smaller pores that did not permit immune cell

125 transmigration ${ }^{16}$. The underlying human pulmonary microvascular endothelium also 


\section{Confidential}

126 forms a continuous planar cell monolayer with cells linked by VE-cadherin containing

127 adherens junctions (Fig. 1b) as it does in vivo.

$128 \quad$ Importantly, the highly differentiated airway epithelium in the Airway Chip

129 expresses higher levels of expression of genes encoding multiple serine proteases

130 involved in viral entry including TMPRSS2, TMPRSS4, TMPRSS11D, and TMPRSS11E

131 (DESC1) compared to MDCK cells that are often used to study influenza virus infection

132 in vitro (Extended Data Fig. 1d); these proteases are essential for the activation and

133 propagation of influenza viruses in vivo. In addition, compared to their initial state upon

134 seeding, differentiation of the airway epithelial cells at an ALI on-chip is accompanied by

135 large increases in protein (Fig. 1c) and mRNA expression levels of the SARS-CoV-2

136 receptor, angiotensin converting enzyme-2 (ACE-2) (Fig. 1d) and the TMPRSS2

137 protease (Fig. 1e) that mediate infection by SARS-CoV-2 ${ }^{18,19}$.

138 When GFP-labeled influenza A/PuertoRico8/34 (H1N1) virus was introduced into

139 the air channel of the microfluidic chip to mimic in vivo infection with airborne virus (Fig.

140 1a), real-time fluorescence microscopic analysis confirmed that the virus infected the

141 human airway epithelial cells (Fig. 1b, Supplementary Movie 1), and this was

142 accompanied by damage to the epithelium, including disruption of tight junctions, loss of

143 apical cilia (Fig. 1b), and compromised barrier function (Fig. 1f). Significantly less

144 infection was detected in undifferentiated airway basal epithelium prior to culture at an

145 ALI on-chip, and there was no detectable direct infection of the endothelium by the virus

146 (Extended Data Fig. 2a). Interestingly, however, influenza A virus infection led to

147 disruption of the lung endothelium on-chip, as evidenced by loss of VE-cadherin 


\section{Confidential}

148 containing adherens junctions (Fig. 1b), which is consistent with the vascular leakage

149 that is induced in lungs of human patients with influenza ${ }^{20}$.

150 Analysis of the replication kinetics of five different influenza A virus strains,

151 including clinical isolates [A/Netherlands/602/2009 (NL/09; H1N1), A/HongKong/8/68

152 (HK/68; H3N2), A/Panama/2007/99 (Pan/99; H3N2)] and cell culture strains [influenza

153 Puerto Rico/8/34 (H1N1), A/WSN/1933 (WSN; H1N1)], showed that all of the virus

154 variants propagate efficiently as demonstrated by large $\left(10^{3}\right.$ - to $10^{4}$-fold) increases in

155 viral titers over 24 to 48 hours in highly differentiated human lung airway epithelium on-

156 chip (Fig. 2a). Notably, the H3N2 virus strains (HK/68 and Pan/99) exhibited $\sim 10$-fold

157 greater replication efficiency than the H1N1 strains (PR8, WSN, and NL/09) (Fig. 2a)

158 and caused severe barrier disruption (Fig. 1f) and more cilia loss (Extended Data Fig.

159 2b). These results corroborate the finding that $\mathrm{H} 3 \mathrm{~N} 2$ is more infectious and virulent, and

160 causes more severe clinical symptoms in humans ${ }^{21}$. Donor-to-donor variability in terms

161 of sensitivity to influenza virus infection was minimal in these studies, as similar viral

162 infectivity was obtained in chips derived from five different healthy epithelial cell donors

163 (Extended Data Fig. 2c).

164 Recruitment of circulating immune cells, such as neutrophils, under dynamic flow

165 to the site of infection in the airway epithelium contributes significantly to influenza A

166 virus pathogenesis in the lung ${ }^{22}$; however, this process has not been well investigated in

167 existing in-vitro models due to their 2D static nature. When primary human neutrophils

168 were perfused through the vascular channel of Airway Chips infected with H1N1 or

169 H3N2 virus, we observed recruitment of these circulating immune cells to the apical

170 surface of the activated lung endothelium within minutes (Fig. $2 \mathbf{b}$ top, Supplementary 


\section{Confidential}

171 Movie 2). This was followed by transmigration of the neutrophils through the

172 endothelium and the ECM-coated pores of the intervening membrane, and up into the

173 airway epithelium over hours (Fig. 2b bottom). The neutrophils targeted the influenza A

174 virus nucleoprotein (NP)-positive infected airway cells (Extended Data Fig. 3) and

175 induced them to coalesce into clusters that decreased in size over time, resulting in

176 clearance of the virus, as evidenced by the disappearance of GFP-positive cells over a

177 period of $1-2$ days (Fig. $\mathbf{2 b}$ bottom). Consistent with the ability of H3N2 virus to induce

178 stronger inflammation relative to $\mathrm{H} 1 \mathrm{~N} 1$ in vivo ${ }^{21}, \mathrm{H} 3 \mathrm{~N} 2$ also stimulated more neutrophil

179 recruitment than $\mathrm{H} 1 \mathrm{~N} 1$ (Fig. 2c), and neutrophil infiltration into the epithelium

180 significantly decreased the viral titers of both H1N1 and H3N2 on-chip (Fig. 2d),

181 consistent with the protective role that neutrophils provide by clearing virus in vivo ${ }^{22}$.

182 H1N1 infection also was accompanied by increased secretion of various inflammatory

183 cytokines and chemokines, including IL-6, IP-10, RANTES, interferon- $\beta$, and MCP-1,

184 which could easily be measured in the effluent from the vascular channel (Fig. 2e).

185 Variations in secretion of proinflammatory mediators in the human lung airway

186 contribute to differences in pathogenesis and morbidity observed for different influenza

187 A virus strains, and analysis of cytokine levels can help clinicians assess disease

188 severity. Thus, we compared the innate immune responses of the human Airway Chip

189 to infection with three patient-derived influenza A virus strains with different virulence:

190 NL/09 (H1N1), Pan/99 (H3N2), and A/HongKong/156/1997 (HK/97; H5N1). When chips

191 were infected with $\mathrm{H} 3 \mathrm{~N} 2$ and $\mathrm{H} 5 \mathrm{~N} 1$ viruses that are known to produce more severe

192 clinical symptoms than $\mathrm{H} 1 \mathrm{~N} 1$ in patients, we found that they also stimulated production

193 of higher levels of cytokines and chemokines, and the most virulent H5N1 strain 
194 induced the highest concentrations (Fig. 2e). These results mirror the clinical finding

195 that patients infected with H5N1 have increased serum concentrations of these

196 inflammatory factors relative to those with H1N1 or H3N2, which significantly contributes

197 to disease pathogenesis ${ }^{21}$.

198 Recapitulation of the effects of clinically used anti-viral therapeutics

199 To explore whether the Airway Chip can be used to evaluate the efficacy of

200 potential antiviral therapeutics, we first tested oseltamivir (Tamiflu), which is the anti-

201 influenza drug most widely used in the clinic. As oseltamivir is metabolized by the liver

202 to release oseltamivir acid in vivo, we introduced this active metabolite into the vascular

203 channel of Airway Chip infected with H1N1 virus, mimicking its blood levels after oral

204 administration. Oseltamivir $(1 \mu \mathrm{M})$ efficiently inhibited influenza A virus replication (Fig.

205 3a), prevented virus-induced compromise of barrier function (Fig. 3b) and disruption of

206 epithelial tight junctions (Fig. 3c), and decreased production of multiple cytokines and

207 chemokines on-chip (Fig. 3d). Importantly, similar anti-influenza efficacy was detected

208 in a randomized controlled trial where treatment with Oseltamivir also led to one log

209 drop in viral titers in nasopharyngeal samples provided by 350 patients $^{23}$. Thus, the

210 Airway Chip faithfully replicates the effects of oseltamivir previously observed in

211 humans, suggesting that it may serve as a useful preclinical model to evaluate potential

212 therapies for virus-induced human lung infections in a preclinical setting.

213 Repurposing of approved drugs as potential anti-influenza therapeutics

214 Given that host serine proteases on human airway epithelial cells play critical

215 roles in influenza A virus propagation ${ }^{12,24}$, and their expression is significantly elevated

216 in the differentiated Airway Chip (Fig. 1e, Extended Data Fig. 1d), we explored 


\section{Confidential}

217 whether existing approved drugs that inhibit serine proteases could suppress infection

218 by delivering them into the airway channel of influenza virus-infected chips (e.g, to

219 mimic intratracheal delivery by aerosol, nebulizer, or inhaler). These studies revealed

220 that two clinically used anticoagulant drugs, nafamostat (Fig. 3e) and trasylol

221 (Extended Data Fig. 4a), significantly reduced influenza H1N1 and H3N2 titers on-chip.

222 Further exploration of nafamostat's actions revealed that it protects airway barrier

223 function (Extended Data Fig. 4b) and tight junction integrity (Extended Data Fig. 4c),

224 and decreases production of cytokines and chemokines (Extended Data Fig. 4d).

225 Nafamostat and the other protease inhibitors appeared to act by efficiently blocking the

226 serine proteases- TMPRSS11D and TMPRSS2-mediated enzymatic cleavage of

227 influenza A viral HA0 protein into HA1 and HA2 subunits (Extended Data Fig. 4e),

228 which is required for viral entry ${ }^{25}$.

When we added nafamostat or oseltamivir at different time points during influenza

230 virus infection on-chip, both nafamostat and oseltamivir exhibited prophylactic and

231 therapeutic effects (Fig. 3f). However, oseltamivir only produced therapeutic effects

232 when was administered within $48 \mathrm{~h}$ post-infection (Fig. 3f). This is consistent with the

233 observation that oseltamivir is only recommended for clinical use within 2 days of

234 influenza virus infection ${ }^{26}$, which is one of the important limitations of using this antiviral

235 therapeutic clinically. Nafamostat also exhibited its inhibitory effects over a $48 \mathrm{~h}$ time

236 period (Fig. 3f). Impressively, however, combined administration of nafamostat and

237 oseltamivir exerted more potent inhibition of influenza virus infection, and this combined

238 regimen was able to double oseltamivir's treatment time window from 48 to 96 hours

239 (Fig. 3f). 


\section{Confidential}

\section{Identification of approved drugs as SARS-CoV-2 entry inhibitors}

Given the faithful recapitulation of human lung responses to influenza infection,

242 we quickly pivoted our effort to focus on SARS-CoV-2 infection when we learned of the

243 emerging COVID-19 pandemic. To alleviate safety concerns and immediately initiate

244 work in a BSL2 laboratory, we designed SARS-CoV-2 pseudoparticles (SARS-CoV-

$2452 \mathrm{pp}$ ) that contain the SARS-CoV-2 spike (S) protein assembled onto luciferase reporter

246 gene-carrying retroviral core particles ${ }^{27}$, based on the genome sequence of SARS-CoV-

2472 released in GenBank on January $12,2020^{28}$. We confirmed the incorporation of

248 SARS-CoV-2 S protein into SARS-CoV-2pp by Western blotting (Extended Data Fig.

249 5a), as previously shown in other pseudotyped SARS-CoV-2 viruses ${ }^{18}$. Successful

250 generation of SARS-CoV-2pp was further confirmed by efficient infection in Huh-7 cells,

251 a human liver cell line commonly used to study infection of SARS viruses ${ }^{29}$, whereas

252 control pseudoparticles without the spike protein of SARS-CoV-2 did not infect

253 (Extended Data Fig. 5b). These pseudotyped S protein-expressing viral particles

254 faithfully reflect key aspects of native SARS-CoV-2 entry into host cells via binding to its

255 ACE2 receptor ${ }^{30}$, and thus, they can be used to test potential entry inhibitors of SARS-

256 CoV-2 ${ }^{18,27}$. Vesicular stomatitis virus (VSV) GP protein pseudoparticles (VSVpp) were

257 also generated and used in parallel studies to exclude toxic and non-specific effects of

258 SARS-CoV-2 entry inhibitors ${ }^{18,27}$.

We then used the Huh-7 cells in a 96-well plate assay format to test the effects of

260 multiple drugs on SARS-CoV-2pp entry that have been approved by the FDA for other

261 medical indications, including chloroquine, hydroxychloroquine, amodiaquine,

262 toremifene, clomiphene, arbidol, verapamil, and amiodarone. These drugs were chosen 


\section{Confidential}

based on the hypothesis that they might have broad-spectrum antiviral activity because they have been shown to inhibit infection by other SARS, influenza, and Ebola viruses ${ }^{31-}$

33. All of these drugs demonstrated dose-dependent inhibition of SARS-CoV-2pp entry in Huh-7 cells without producing any detectable cell toxicity (Extended Data Fig. 6) when added at 1 and $5 \mu \mathrm{M}$ simultaneously with the virus and culturing for 72 hours (Fig. 4a). These results were promising; however, Huh-7 cells only express low levels of ACE2 $2^{34}$ and they do not express TMPRSS2 $2^{29,35}$. In addition, this cell line was derived from a human liver tumor, whereas SARS-CoV-2 preferentially targets lung in humans. Thus, to test the clinical translation potential of the drugs that were active in the Huh-7 cell assay, we evaluated their ability to prevent SARS-CoV-2pp infection in the more highly differentiated and physiologically relevant human Lung Airway Chips. SARS-CoV-2pp were introduced into the air channel of the Airway Chips to mimic human infection by airborne SARS-CoV-2. High levels of the viral pol gene encoded by the SARS-CoV-2pp were detected in the lung airway epithelial cells in chips infected by SARS-CoV-2pp within 48 hours, but not in control chips that were inoculated with pseudoparticles without SARS-CoV-2 spike protein (Extended Data Fig. 7a). Infection with SARS-CoV-2pp was also blocked by a neutralizing antibody that targets the 280 receptor binding domain (RBD) of SARS-CoV-2 (Extended Data Fig. 7b), confirming 281 that entry of the pseudotyped SARS-CoV-2 virus into the epithelial cells of the human 282 Lung Airway Chip is mediated specifically by the SARS-CoV-2 S protein. The ability of 283 SARS-CoV-2pp to efficiently infect human airway epithelial cells on-chip is consistent 284 with our finding that these highly differentiated lung cells express high levels of its ACE2 285 receptor as well as TMPRSS2 (Fig. 1c-e), which mediate cellular entry of native SARS- 


\section{Confidential}

CoV-2 virus ${ }^{18,19}$. In addition, immunofluorescence microscopic analysis confirmed that the SARS-CoV-2pp preferentially infected ciliated cells in the human Lung Airway Chip (Extended Data Fig. 7c), as native SARS-CoV-2 virus does in vivo ${ }^{19}$. for 24 hours with amodiaquine, toremifene, clomiphene, chloroquine, hydroxychloroquine, arbidol, verapamil, or amiodarone at clinically relevant levels similar to their maximum concentration $\left(\mathrm{C}_{\max }\right)$ in blood reported in humans (Table 1) to 294 introduced into the airway channel and incubated statically while continuously flowing 295 the drug through the vascular channel for additional 48 hours. qPCR quantitation of viral 296 mRNA revealed that only three of these drugs - amodiaquine, toremiphene, and 297 clomiphene — significantly reduced viral entry (by $59.1 \%, 51.1 \%$ and $28.1 \%$, respectively) (Fig. 4b) without producing detectable cytotoxicity (Extended Data Fig. 6b) under these more clinically relevant experimental conditions. Importantly, hydroxychloroquine, chloroquine, and arbidol that have no effect on SARS-CoV-2pp

302 clinical trials ${ }^{1,2,36}$. When administered to patients, the most potent drug amodiaquine is 303 rapidly transformed (half life $\sim 5 \mathrm{hr}$ ) into its active metabolite, desethylamodiaquine, 304 which has a much longer half-life ( 9-18 days $)^{37}$. When desethylamodiaquine was 305 administered at a clinically relevant dose $(1 \mu \mathrm{M}$; Table 1) in the human Airway Chips, it 306 also reduced entry of the pseudotyped SARS-CoV-2 viral particles by $\sim 60 \%$ (Extended 307 Data Fig. 8) suggesting that both amodiaquine and its metabolite are active inhibitors of 308 SARS-CoV-2 S protein-dependent viral entry. 


\section{Amodiaquine and desethylamodiaquine inhibit SARS-CoV-2 infection in vitro and} in vivo

Finally, we tested the ability of the most potent drug identified in the Airway Chip,

312 amodiaquine, and its metabolite desethylamodiaquine to inhibit infection by GFP-

313 labeled SARS-CoV-2 virus at a multiplicity of infection $(\mathrm{MOI}=0.1)$ in Vero E6 cells. We

314 found that both compounds inhibited infection by SARS-CoV-2 in a dose-dependent

315 manner (Fig. 5a) with half maximal inhibitory concentrations (IC50) of $10.3 \pm 1.6$ and 8.5

$316 \pm 3.0 \mu \mathrm{M}$ for amodiaquine and desethylamodiaquine, respectively. Amodiaquine and

317 desethylamodiaquine also inhibited infection by wild type SARS-CoV-2 virus when

318 administered under less stringent conditions $(\mathrm{MOI}=0.01)$, with both compounds

319 exhibiting $\mathrm{IC}_{50}<5 \mu \mathrm{M}$. In addition, amodiaquine reduced viral load by $\sim 3$ logs in ACE2-

320 expressing human lung A549 cells infected with native SARS-CoV-2 when administered $321 \quad$ at $10 \mu \mathrm{M}$ (Fig. 5b).

Given this potent inhibitory activity against native SARS-CoV-2, we then evaluated amodiaquine in a hamster COVID-19 model in which the animals are infected intranasally with SARS-CoV-2 virus (103 PFU). The animals were treated once a day for 4 days with amodiaquine (50 mg/kg via subcutaneous injection) beginning one day prior to SARS-CoV-2 infection. The dosing regimen was selected based on a PK study for

327 amodiaquine that was carried out in healthy hamsters in parallel. A single dose of 328 amodiaquine $(50 \mathrm{mg} / \mathrm{kg})$ injected subcutaneously revealed that the $\mathrm{C}_{\max }$ for 329 amodiaquine and its active metabolite desethylamodiaquine were $\sim 3.2$ and $0.7 \mu \mathrm{M}$, 330 respectively; while the $\mathrm{T}_{1 / 2}$ for amodiaquine was 18.1 hours, that of its active metabolite 331 was significantly greater than the 1 day timecourse analyzed (Extended Data Fig. 


\section{Confidential}

$3329 a, b)$, which is consistent with human clinical data ${ }^{37}$. Analysis of drug concentrations in

333 lung, kidney, intestine, and heart revealed that both drugs became concentrated in

334 these organs relative to plasma (Extended Data Fig. 9c). Analysis of drug

335 concentrations 24 hours after dosing revealed significant exposures of amodiaquine and

336 desethylamodiaquine in lung, kidney, and intestine (Extended Data Fig. 9c), with levels

337 in tissues relative to plasma enhanced 21 - to 138 -fold for amodiaquine and 8- to 45 -fold

338 for desethylamodiaquine. These PK results, including the extended half lives and tissue

339 concentration for both compounds are consistent with results of past PK studies in

$340 \quad$ humans $^{37}$.

341 Importantly, amodiaquine treatment of infected hamsters resulted in $\sim 70 \%$

342 reduction in SARS-CoV-2 viral load measured by RT-qPCR of the viral N transcript

343 when measured 3 days after the viral challenge (Fig. 5c). Immunohistochemical

344 analysis of lungs from these animals confirmed that amodiaquine treatment resulted in a

345 significant reduction in expression of SARS-CoV-2 N protein in these tissues (Fig. 5 d).

346 We then carried out studies using a SARS-CoV-2 transmission model in which vehicle

347 or amodiaquine-treated healthy animals are placed in the same cage with animals that

348 had been infected with SARS-CoV-2 virus one day earlier. In vehicle controls, this

349 experimental setup results in a 100\% transmission within two days of exposure. In

350 contrast, the same amodiaquine treatment regimen as described above resulted in a

$35190 \%$ inhibition of SARS-CoV-2 infection as measured by quantifying $\mathrm{N}$ transcript levels

352 (Fig. 5e). These results were further corroborated in an independent experiment where

353 amodiaquine-treated animals showed a greater than one log decrease in viral titers

354 measured by plaque assays when compared to vehicle (Fig. 5f). To our knowledge, this 


\section{Confidential}

355 is the first example of successful chemoprophylaxis against SARS-CoV-2 in vivo. Taken

356 together, these results confirm that the antiviral activities identified in the human Lung

357 Airway Chips translate to the in vivo setting, and suggest that amodiaquine may provide 358 significant protection when taken prophylactically.

\section{Discussion}

Taken together, these data show that human Organ Chips, such as the Lung Airway Chip, can be used to rapidly identify existing approved drugs that may be repurposed for pandemic virus applications in crisis situations that require accelerated development of potential therapeutic and prophylactic interventions. Our work on repurposing of therapeutics for COVID-19 was initiated on January 13, 2020 (1 day after

367 drugs in Airway Chips were obtained three weeks later. The ability to apply drugs using dynamic fluid flow on-chip enables the human lung cells to be treated with more clinically relevant dynamic drug exposures on-chip. While drugs were administered at levels similar to their $\mathrm{C}_{\max }$ here to compare relative potencies, one caveat is that we did not quantify drug absorption or protein binding in this study. Importantly, by carrying out mass spectrometry measurements of drug levels in these devices, full PK profiles can be recapitulated in these Organ Chip models ${ }^{8}$, which should further aid clinical translation in the future. While animal models remain the benchmark for validation of therapeutics to move to humans, it is important to note that human Organ Chips are now being explored as viable alternatives to animal models ${ }^{38}$ and regulatory agencies are encouraging pharmaceutical and biotechnology companies to make use of data 


\section{Confidential}

378 from Organ Chips and other microphysiological systems in their regulatory

379 submissions ${ }^{39}$.

These studies led to the identification of multiple approved drugs that could serve

381 as prophylactics and therapeutics against viral pandemics. The anticoagulant drug,

382 nafamostat, significantly extended the current treatment time window of oseltamivir from

3832 to 4 days after infection by influenza virus, which could have great clinical relevance

384 given that most patients do not begin treatment until days after they are infected.

385 Similarly, while the human Organ Chip model successfully predicted the inability of

386 chloroquine, hydroxychloroquine, and arbidol to work in animals ${ }^{4}$ and human

387 patients ${ }^{1,2,40}$, in contrast with what was reported in cell lines ${ }^{41,42}$, we successfully

388 identified amodiaquine as a putative therapeutic for SARS-CoV-2 that works both in

389 vitro and in vivo. Amodiaquine is an anti-malarial drug related to chloroquine and

390 hydroxychloroquine ${ }^{43}$. This drug was the most potent inhibitor of SARS-CoV-2pp entry

391 into human airway cells, producing $\sim 60 \%$ inhibition when administered under flow at

$392 \quad 1.24 \mu \mathrm{M}$, which should be clinically achievable in the plasma of patients with malaria

393 who receive $300 \mathrm{mg}$ administration ${ }^{44}$, as well as in tissues such as lung where the drug

394 and its metabolite concentrate ${ }^{37}$. Importantly, further investigation of amodiaquine

395 revealed that both this drug and its active metabolite (desethylamodiaquine) do indeed

396 inhibit native SARS-CoV-2 infection in vitro and in vivo. Thus, these findings suggest

397 that the microfluidic human Organ Chip model, combined with existing preclinical cell-

398 based and animal assays, offers a potentially more clinically relevant test bed for

399 accelerated discovery of anti-COVID-19 drugs. 


\section{Confidential}

When considering repurposing of approved drugs for COVID-19, it is important to recognize that every drug has its own distinct therapeutic and toxicity profile that must be taken into consideration. Amodiaquine has been widely used for prophylaxis and treatment of malaria for over 60 years. It is currently used in low resource nations where the World Health Organization (WHO) recommends it be used in combination with artesunate for chemoprophylaxis of malaria and as a second line acute treatment for uncomplicated $P$. falciparum-resistant malaria. Interestingly, the amodiaquineartesunate drug combination also has been reported to lower the risk of death from Ebola virus disease ${ }^{45}$. But amodiaquine was withdrawn from use in the United States due to rare occurrence of agranulocytosis and liver damage with high doses or prolonged treatment ${ }^{46}$; however, it continues to be well tolerated among African populations where it is commonly administered for short duration ( 3 day course). The short course is possible because the half life of amodiaquine's active metabolite, desethylamodiaquine, is very long (on the order of 9 to 18 days) and it concentrates in organs, including lung ${ }^{37}$.

Given the alarming rate at which the SARS-CoV-2 pandemic is spreading, clinicians must seriously consider the relative risks and benefits of using any existing approved drug as a new COVID-19 therapy with specific patient populations (e.g., male versus female, young versus old, Caucasian versus African, etc.) before initiating any trial in their local communities. Our findings raise the possibility that amodiaquine could be explored as a chemoprophylaxis therapy to prevent spread of COVID-19 and help people return to their workplace by treating healthy patients for 3 days, which could then offer protection for an additional 2 weeks. If amodiaquine were to be advanced to 


\section{Confidential}

423 clinical trials for prevention of COVID-19, it would be critical to select patient populations

424 carefully and appropriate clinical assessments (e.g., blood and liver function tests)

425 should be carried out before and during administration of drug. This prophylactic

426 therapy may be particularly valuable in Africa and other low resource nations where this

427 inexpensive drug is more readily available and where more expensive alternative

428 therapies are not feasible.

The current COVID-19 pandemic and potential future ones caused by influenza

430 viruses or other coronaviruses, represent imminent dangers and major ongoing public

431 health concerns. When it comes to repurposing existing antiviral agents, every

432 experimental assay has its limitations. However, our results suggest that combining

433 multiplexed cell-based assays with lower throughput/higher content human Organ Chips

434 that recapitulate human-relevant responses as well as animal models, and focusing on

435 compounds that are active in all models, could provide a fast track to identify potential

436 treatments for the current COVID-19 pandemic that have a higher likelihood of working

437 in human patients. This discovery pipeline may be equally valuable to combat

438 unforeseen biothreats, such as new pandemic influenza or coronavirus strains, in the 439 future.

\section{METHODS}

Human Airway Chip Culture. Microfluidic two-channel Organ Chip devices

444 Each microdevice contains two adjacent parallel microchannels (apical, $1 \mathrm{~mm}$ wide $\times 1$

$445 \mathrm{~mm}$ high; basal, $1 \mathrm{~mm}$ wide $\times 0.2 \mathrm{~mm}$ high; length of overlapping channels, $16.7 \mathrm{~mm}$ ) 


\section{Confidential}

446 separated by the porous membrane. Similar results were also obtained in some studies

447 not involving immune cell recruitment using 2-channel devices fabricated from poly-

448 dimethyl siloxane with a PET membrane containing 0.4 um pores, as used in past

449 Airway Chip studies ${ }^{16}$. Before cell plating, both channels of these devices were washed

450 with $70 \%$ ethanol, filled with $0.5 \mathrm{mg} / \mathrm{mL}$ ER1 solution in ER2 buffer (Emulate Inc.) and

451 placed under UV lamp (Nailstar, NS-01-US) for $20 \mathrm{~min}$ to activate the surface for protein

452 coating. The channels were then washed sequentially with ER2 buffer and PBS. The

453 porous membranes were coated on both sides with collagen type IV from human

454 placenta $(0.5 \mathrm{mg} / \mathrm{mL}$ in water; Sigma-Aldrich) at room temperature overnight. The

455 solution was then aspirated from the chip, which was then used for seeding cells.

456 Primary human lung airway epithelial basal stem cells (Lonza, USA; Catalog \#: CC-

4572540 ) obtained from healthy donors $448571,446317,623950,485960$, and 672447 )

458 were expanded in $75 \mathrm{~cm}^{2}$ tissue culture flasks using airway epithelial cell growth

459 medium (Promocell, Germany) until $60-70 \%$ confluent. Primary human pulmonary

460 microvascular endothelial cells (Cell Biologics, USA) were expanded in $75 \mathrm{~cm}^{2}$ tissue

461 culture flasks using human endothelial cell growth medium (Cell Biologics, USA) until

$462 \quad 70-80 \%$ confluent.

463 To create the human Airway Chips, endothelial cells $\left(2 \times 10^{7}\right.$ cells $\left./ \mathrm{mL}\right)$ were first

464 seeded in the bottom channel by inverting the chip for $4 \mathrm{~h}$ in human endothelial cell

465 growth medium, followed by inverting the chip again and seeding of the top channel with

466 the lung airway epithelial basal stem cells $\left(2.5 \times 10^{6} \mathrm{cells} / \mathrm{mL}\right)$ for $4 \mathrm{~h}$ in airway epithelial

467 cell growth medium. The respective medium for each channel was refreshed and the

468 chips were incubated under static conditions at $37^{\circ} \mathrm{C}$ under $5 \% \mathrm{CO}_{2}$ overnight. The 


\section{Confidential}

adherent cells were then continuously perfused with the respective cell culture medium using an IPC-N series peristaltic pump (Ismatec) or Zoe (Emulate) at a volumetric flow rate of $60 \mu \mathrm{L} / \mathrm{h}$. After 5-7 days, the apical medium was removed while allowing air to fill the channel to establish an ALI, and the airway epithelial cells were cultured for 3-4 additional weeks while being fed only by constant flow of PneumaCult-ALI medium (StemCell) supplemented with $0.1 \%$ VEGF, $0.01 \% \mathrm{EGF}$, and $1 \mathrm{mM} \mathrm{CaCl}_{2}$ from an Endothelial Cell Medium Kit (Cell Biological, M1168) through the bottom vascular channel. The chips were cultured in an incubator containing $5 \% \mathrm{CO}_{2}$ and $16-18 \% \mathrm{O}_{2}$ at $85-95 \%$ humidity, and the apical surface of the epithelium was rinsed once weekly with PBS to remove cellular debris and mucus. Highly differentiated human airway structures and functions can be maintained in the human lung Airway Chip for more than 2 months.

Immunofluorescence microscopy. Cells were washed with PBS through the apical and basal channels, fixed with 4\% paraformaldehyde (Alfa Aesar) for 20-25 min, and then washed with PBS before being stored at $4^{\circ} \mathrm{C}$. Fixed tissues were permeabilized on-chip with $0.1 \%$ Triton X-100 (Sigma-Aldrich) in PBS for 5 min, exposed to PBS with $10 \%$ goat serum (Life Technologies) and $0.1 \%$ Triton $\mathrm{X}-100$ for 30 min at room temperature, and then incubated with primary antibodies (Supplementary Table 2) diluted in incubation buffer (PBS with $1 \%$ goat serum and $0.1 \%$ Triton $X-100$ ) overnight at $4^{\circ} \mathrm{C}$, followed by incubation with corresponding secondary antibodies (Supplementary Table 2) for $1 \mathrm{~h}$ at room temperature; nuclei were counterstained with DAPI (Invitrogen) after secondary antibody staining. Fluorescence imaging was carried 


\section{Confidential}

491 out using a confocal laser-scanning microscope (SP5 X MP DMI-6000, Germany) and

492 image processing was done using Imaris software (Bitplane, Switzerland).

$493 \quad$ Barrier function assessment. To measure tissue barrier permeability, $50 \mu \mathrm{l}$ cell

494 medium containing Cascade blue (607 Da) (50 $\mu \mathrm{g} / \mathrm{mL}$; Invitrogen) was added to bottom

495 channel and $50 \mu \mathrm{l}$ cell medium was added to top channel. The fluorescence intensity of

496 medium of top and bottom channels was measured $2 \mathrm{~h}$ later in three different human

497 Airway chips. The apparent permeability was calculated using the formula: $\mathrm{Papp}=J /(A \times$

$498 \Delta \mathrm{C}$ ), where $\mathrm{Papp}$ is the apparent permeability, $J$ is the molecular flux, $A$ is the total area

499 of diffusion, and $\Delta \mathrm{C}$ is the average gradient.

$500 \quad$ Mucus quantification. Mucus present in the airway channel was isolated by

501 infusing $50 \mu \mathrm{l}$ PBS into the upper channel of the Airway Chip, incubating for $1 \mathrm{~h}$ at $37^{\circ} \mathrm{C}$,

502 and then collecting the fluid and storing it at $-80^{\circ} \mathrm{C}$ before analysis, as previously

503 described $^{6}$. Quantification of mucus production was carried out by quantifying Alcian

504 Blue Staining (Thermo Fisher Scientific) and comparing to serially diluted standards of

505 mucin (Sigma-Aldrich) in PBS.

Quantitative reverse transcription-polymerase chain reaction (RT-qPCR). Total

507 RNA was extracted from differentiated human Airway chips, pre-differentiated lung

508 airway epithelial cells, or MDCK cells using TRIzol (Invitrogen). cDNA was then

509 synthesized using AMV reverse transcriptase kit (Promega) with Oligo-dT primer. To

510 detect cellular gene-expression level, quantitative real-time PCR was carried out

511 according to the GoTaq qPCR Master Mix (Promega) with $20 \mu$ of a reaction mixture

512 containing gene-specific primers (Supplementary Table 3). The expression levels of

513 target genes were normalized to GAPDH. 
Influenza viruses. Influenza virus strains used in this study include A/PR/8/34 (H1N1), GFP-labeled A/PR/8/34 (H1N1), A/WSN/33 (H1N1), A/Netherlands/602/2009 (H1N1), A/Hong Kong/8/68/ (H3N2), A/Panama/2007/99 (H3N2), and A/Hong Kong/156/1997 (H5N1). A/PR/8/34 (H1N1), GFP-labeled A/PR/8/34 (H1N1), A/WSN/33 (H1N1) were generated using reverse genetics techniques. Other viruses were obtained from the Centers for Disease Control and Prevention (CDC) or kindly shared by Drs. P. Palese, R.A.M. Fouchier, and A. Carcia-Sastre. infected with influenza viruses by flowing 30 uL of PBS containing the indicated multiplicity of infection (MOI) of viral particles into the apical channel, incubating for $2 \mathrm{~h}$ at $37^{\circ} \mathrm{C}$ under static conditions, and then removing the medium to reestablish an ALI. To measure virus propagation, the apical channel was incubated with $50 \mu$ of PBS for $1 \mathrm{~h}$ at $37^{\circ} \mathrm{C}$ at various times, and then the apical fluid and vascular effluent were collected from the apical and basal channels, respectively, to quantify viral load using the plaque

528 formation assay; released cytokines and chemokines were analyzed in these same 529 samples. The tissues cultured on-chip were also fixed and subjected to $530 \quad$ immunofluorescence microscopic analysis.

531 To test the efficacy of oseltamivir acid, Airway Chips infected with influenza virus $532(\mathrm{MOI}=0.1)$ were treated with $1 \mu \mathrm{M}$ oseltamivir acid (Sigma-Aldrich) under flow $(60 \mu \mathrm{l} / \mathrm{h})$ 533 through the vascular channel. To explore the effects of serine protease inhibitors on 534 influenza infection, Nafamostat (Abcam) or Trasylol (G-Biosciences) was delivered into 535 the airway channel of influenza-infected chip ( $\mathrm{MOI}=0.1)$. Two days later, the virus 536 samples were collected for detection of viral load and the vascular effluents were 


\section{Confidential}

537 collected for analysis of cytokines and chemokines. In the treatment time window

538 detection experiment, oseltamivir acid $(1 \mu \mathrm{M})$, nafamostat $(10 \mu \mathrm{M})$, or both were added

539 to the influenza $\mathrm{H} 1 \mathrm{~N} 1$-infected Airway Chips $(\mathrm{MOI}=0.1)$ at indicated times. Oseltamivir

540 was perfused through the vascular channel, while nafamostat was introduced in $20 \mathrm{uL}$

541 of PBS and incubated in the airway channel for 48 hours. Fluids samples were then

542 collected from both channels for detection of viral load.

543 Analysis of neutrophil infiltration. Neutrophils isolated from fresh human blood

544 using a Ficoll-Paque PLUS (GE Healthcare) gradient were resuspended in medium at a

545 concentration of $5 \times 10^{6}$ cells $/ \mathrm{mL}$, which is within the normal range $\left(2.5-7.5 \times 10^{6}\right.$

546 cells $/ \mathrm{ml}$ ) of neutrophils found in human blood. The isolated neutrophils were labeled with

547 Cell Tracker Red CMTPX (Invitrogen) and injected into the vascular channel of inverted

548 Airway Chips infected with influenza virus $(\mathrm{MOI}=0.1)$ at a flow rate of $50-100 \mu \mathrm{L} / \mathrm{h}$

549 using a syringe pump; $2 \mathrm{~h}$ later unbound neutrophils were washed away by flowing cell-

550 free medium for $24 \mathrm{~h}$. Virus samples were collected by incubating the airway channel

551 with $50 \mu \mathrm{l}$ of PBS for $1 \mathrm{~h}$ at $37^{\circ} \mathrm{C}$, collecting the fluid, and detecting virus load using the

552 plaque assay. The cell layers were fixed on-chip and subjected to immunofluorescence

553 microscopic analysis for influenza virus NP (Invitrogen) and neutrophils (CD45,

554 Biolegend). Micrographs of four or five random areas were taken from chips for

555 subsequent quantification of infiltrated neutrophils. To study the interaction between

556 influenza virus and neutrophils, Airway Chips were infected with GFP-labeled PR8 virus

$557(\mathrm{MOI}=0.1)$ for $24 \mathrm{~h}$. Cell Tracker Red CMTPX-labeled neutrophils $\left(5 \times 10^{6} \mathrm{cells} / \mathrm{mL}\right)$

558 were perfused in medium through the vascular channel of infected Airway Chips.

559 Immunofluorescence microscopic analysis were carried out at indicated times. 
Plaque formation assay. Virus titers were determined using plaque formation assays. Confluent MDCK cell monolayers in 12-well plate were washed with PBS, inoculated with $1 \mathrm{~mL}$ of 10 -fold serial dilutions of influenza virus samples, and incubated for $1 \mathrm{~h}$ at $37^{\circ} \mathrm{C}$. After unabsorbed virus was removed, the cell monolayers were overlaid with $1 \mathrm{~mL}$ of DMEM (Gibco) supplemented with 1.5\% low melting point agarose (SigmaAldrich) and $2 \mu \mathrm{g} / \mathrm{mL}$ TPCK-treated trypsin (Sigma-Aldrich). After incubation for 2-4 days at $37^{\circ} \mathrm{C}$ under $5 \% \mathrm{CO}_{2}$, the cells were fixed with $4 \%$ paraformaldehyde, and stained with crystal violet (Sigma-Aldrich) to visualize the plaques; virus titers were determined as plaque-forming units per milliliter (PFU/mL). Plaque titers from in vivo lung samples were determined post mortem by complete lung dissection and dissociation in PBS. Debris was pelleted a 5000 rpm and the remaining supernatant was used to determine PFU/mL.

Analysis of cytokines and chemokines. Vascular effluents from Airway Chips were collected and analyzed for a panel of cytokines and chemokines, including IL-6, IP-10, MCP-1, RANTES, interferon- $\beta$, using custom ProcartaPlex assay kits (Invitrogen). Analyte concentrations were determined using a Luminex100/200 Flexmap3D instrument coupled with Luminex XPONENT software (Luminex, USA). Analysis of cleavage of virus hemagglutinin (HA) by serine proteases. For analysis of HA cleavage by serine proteases in the presence or absence of nafamostat, MDCK cells $\left(5 \times 10^{5}\right.$ cells per well in 6 -well plates) were transfected with $2.5 \mu \mathrm{g}$ serine protease expression plasmid or empty vector using TransIT-X2 Dynamic Delivery System (Mirus). One day later, the cells were infected with influenza A/WSN/33 (H1N1) virus $(\mathrm{MOI}=0.01)$ in DMEM supplemented with $1 \% \mathrm{FBS}$, and then cultured in the 


\section{Confidential}

583 presence or absence of $10 \mu \mathrm{M}$ nafamostat. Two days post-infection, the supernatant

584 was harvested and subjected to Western blot analysis using anti-HA1 antibody.

585 Drugs for the SARS-CoV2pp studies. Chloroquine (cat. \#ab142116),

586 Hydroxychloroquine (cat. \#ab120827), arbidol (cat. \#ab145693), toremifene (cat.

$587 \quad$ \#ab142467), clomiphene (cat. \#ab141183), verapamil (cat. \#ab146680), and

588 amiodarone (cat. \#ab141444) were purchased from Abcam; amodiaquine

589 dihydrochloride dihydrate (cat. \#A2799) was purchased from Sigma-Aldrich; N-

590 desethylamodiaquine (cat. \#20822) was purchased from Caymanchem. Chloroquine

591 was dissolved in water to a stock concentration of $10 \mathrm{mM}$; all other tested drugs were

592 dissolved in dimethyl sulfoxide (DMSO) to a stock concentration of $10 \mathrm{mM}$. The purity of

593 all evaluated drugs was $>95 \%$.

594 Plasmids. Plasmid expressing the spike protein of SARS-CoV-2 (pCMV3-SARS-

595 CoV2-Spike) was purchased from Sino Biological Inc. (Beijing, China). pCMV-VSVG,

596 pNL4-3.Luc.R-E-, and pAdvantage were obtained from Addgene, NIH AIDS Reagent

597 Program, and Promega, respectively. All plasmids used for transfection were amplified

598 using the Maxiprep Kit (Promega) according to the manufacturer's instructions.

599 Pseudotyped virus production. HEK293T cells $\left(5 \times 10^{5}\right.$ cell per well) were seeded

600 into 6-well plates. $24 \mathrm{~h}$ later, HEK293T cells were transfected with $1.0 \mu \mathrm{g}$ of pNL4-

601 3.Luc.R-E-, $0.07 \mu \mathrm{g}$ of pCMV3-SARS-CoV-2-Spike, and $0.3 \mu \mathrm{g}$ of pAdvantage with the

602 TransIT-X2 transfection reagent (Mirus) according to the manufacturer's instructions to

603 produce SARS-CoV-2 spike pseudotyped HIV virions (SARS-CoV-2pp). Similarly,

604 HEK293T cells were transfected with $1.0 \mu \mathrm{g}$ of pNL4-3.Luc.R-E-, $0.7 \mu \mathrm{g}$ of pCMV-

605 VSVG, and $0.3 \mu \mathrm{g}$ of pAdvantage to produce VSVG pseudotyped HIV virions (VSVpp). 
606 The supernatants containing the pseudotyped viruses were collected at $48 \mathrm{~h}$ post-

607 transfection and clarified by the removal of floating cells and cell debris with

608 centrifugation at $10^{3} \mathrm{~g}$ for $5 \mathrm{~min}$. The culture supernatants containing pseudotyped

609 viruses particles were either used immediately or flash frozen in aliquots and stored at

$61080^{\circ} \mathrm{C}$ until use after being concentrated using a PEG virus precipitation kit (Abcam).

611 Incorporation of the SARS-CoV-2 S protein into the SARS-CoV-2pp was confirmed

612 using Western Blot analysis with anti-SARS-CoV-2 S1 chimeric monoclonal antibody

613 with combined constant domains of the human IgG1 molecule and mouse variable

614 regions (40150-D001 Sinobiological, 1:500); a recombinant receptor binding domain

615 (RBD) fragment from the $\mathrm{S} 1$ region was used as a control (BEI resources, NR-52306).

616 Similar results were also obtained using a commercially available pseudotyped SARS-

617 CoV-2 S protein expressing viral particles (Amsbio LLC).

Infection assay using pseudotyped viruses in Huh-7 cells. Drugs were tested using entry assays for SARS-CoV-2pp and VSVpp, as previously described ${ }^{27}$. Infections

620 were performed in 96-well plates. SARS-CoV-2pp or VSVpp was added to $5 \times 10^{3}$ Huh-

6217 cells (a human liver cell line) per well in the presence or absence of the test drugs or

622 compounds. The mixtures were then incubated for 72 hours at $37^{\circ} \mathrm{C}$. Luciferase activity, 623 which reflects the number of pseudoparticles in the host cells, was measured at $72 \mathrm{~h}$

624 post-infection using the Bright-Glo reagent (Promega) according to the manufacturer's 625 instructions. Test drugs were serially diluted to a final concentration of 1 or $5 \mu \mathrm{M}$. The 626 maximum infectivity (100\%) was derived from the untreated wells; background $(0 \%)$

627 from uninfected wells. To calculate the infection values, the luciferase background 628 signals were subtracted from the intensities measured in each of the wells exposed to 


\section{Confidential}

629 drug, and this value was divided by the average signals measured in untreated control

630 wells and multiplied by $100 \%$.

631 SARS-CoV-2pp infection of human lung Airway Chips. To measure infection in

632 human Airway Chips with the pseudotyped virus, drugs were flowed through the

633 vascular channel of the Airway Chips at their reported $\mathrm{C}_{\max }$ in human blood (Table 2)

634 while airway channel was statically treated with the same concentrations of drugs. $24 \mathrm{~h}$

635 later, the SARS-CoV-2pp was delivered into the airway channel in a small volume (30

$636 \mu \mathrm{L}$ ) of medium containing the drug at the same concentrations and incubated statically

637 for additional $48 \mathrm{~h}$ while the drug at the same dose was continuously flowed through the

638 vascular channel at $37^{\circ} \mathrm{C}$. The lung airway epithelium was then collected by RNeasy

639 Micro Kit (Qiagen) according to the manufacturer's instructions and subjected to

640 analysis of viral load by qRT-PCR. As we only focused in assessing viral entry in these

641 studies, the chips were only lined by differentiated airway epithelium and did not contain

642 endothelium.

Native SARS-CoV-2 in vitro infection assay. All work with native SARS-CoV-2

644 virus was performed in a Biosafety Level 3 laboratory and approved by our Institutional

645 Biosafety Committee. Vero E6 cells (ATCC\# CRL 1586) were cultured in DMEM

646 (Quality Biological), supplemented with 10\% (v/v) heat inactivated fetal bovine serum

647 (Sigma), 1\% (v/v) penicillin/streptomycin (Gemini Bio-products), and 1\% (v/v) L-

648 glutamine (2 mM final concentration, Gibco) (Vero Media). Cells were maintained at

$64937^{\circ} \mathrm{C}(5 \%$ CO2). GFP-labeled native SARS-CoV-2 was generously provided by Dr.

650 Ralph S. Baric ${ }^{47}$. Stocks were prepared by infection of Vero E6 cells for two days when

651 CPE was starting to become visible. Media were collected and clarified by centrifugation 
652 prior to being aliquoted for storage at $-80^{\circ} \mathrm{C}$. Titer of stock was determined by plaque 653 assay using Vero E6 cells. GFP-labeled native SARS-CoV-2 infection and drug testing 654 were performed in Vero E6 cells 1. Cells were plated in clear bottom, black 96-well 655 plates one day prior to infection. Drug was diluted from stock to $50 \mu \mathrm{M}$ and an 8-point $656 \quad 1: 2$ dilution series prepared in duplicate in Vero Media. Each drug dilution and control 657 was normalized to contain the same concentration of drug vehicle (e.g., DMSO). Cells 658 were pre-treated with drug for $2 \mathrm{~h}$ at $37^{\circ} \mathrm{C}(5 \% \mathrm{CO})$ prior to infection with SARS-CoV-2 659 at $\mathrm{MOI}=0.1$. Plates were then incubated at $37^{\circ} \mathrm{C}(5 \% \mathrm{CO} 2)$ for $48 \mathrm{~h}$, followed by 660 fixation with 4\% PFA, nuclear staining with Hoechst (Invitrogen), and data acquisition on 661 a Celigo 5-channel Imaging Cytometer (Nexcelom Bioscience, Lawrence, CA). The 662 percent of infected cells was determined for each well based on GFP expression by 663 manual gating using the Celigo software. In addition to plates that were infected, parallel 664 plates were left uninfected to monitor cytotoxicity of drug alone. Plates were incubated 665 at $37^{\circ} \mathrm{C}(5 \% \mathrm{CO})$ for $48 \mathrm{~h}$ before performing CellTiter-Glo (CTG) assays as per the 666 manufacturer's instruction (Promega, Madison, WI). Luminescence was read on a 667 BioTek Synergy HTX plate reader (BioTek Instruments Inc., Winooski, VT) using the 668 Gen5 software (v7.07, Biotek Instruments Inc., Winooski, VT). Similar results were 669 obtained with wild type SARS-CoV-2 virus, using a previously published method ${ }^{45}$. $670 \quad$ Hamster PK studies. Amodiaquine dihydrochloride dihydrate (Sigma, \#A2799) was 671 formulated at $10 \mathrm{mg} / \mathrm{ml}$ in $12 \%$ sulfobutylether- $\beta$-cyclodextrin in water at $\mathrm{pH} 5.0$ and 672 administered to LVG male hamsters $(n=3)$ at $50 \mathrm{mg} / \mathrm{kg}$ by subcutaneous injection (dose 673 volume of $5 \mathrm{ml} / \mathrm{kg}$ ). Blood samples were drawn at $0.5,1,2,4,8$ and 24 hours and 674 plasma was prepared. At 24 hours, animals were anesthetized and then perfused to 
675 clear tissues of blood. Tissues of interest (lung, heart, kidney and intestine) were

676 removed and homogenized at a 1:3 (w/v) ratio in water. The desired serial

677 concentrations of working reference analyte solutions of amodiaquine (Selleckchem)

678 and desethylamodiaquine (Cayman Biochemicals) were achieved by diluting stock

679 solution of analyte with $50 \%$ acetonitrile $(0.1 \%$ Formic acid) in water solution. $20 \mu \mathrm{L}$ of

680 working solutions were added to $20 \mu \mathrm{L}$ of the blank LVG hamster plasma to achieve

681 calibration standards of 1 to $1000 \mathrm{ng} / \mathrm{mL}$ in a total volume of $40 \mu \mathrm{L} .40 \mu \mathrm{L}$ standards, 40

$682 \mu \mathrm{L} \mathrm{QC}$ samples and $40 \mu \mathrm{L}$ unknown samples (20 $\mu \mathrm{L}$ plasma with $20 \mu \mathrm{L}$ blank solution)

683 were added to $200 \mu \mathrm{L}$ of acetonitrile containing internal standard and $0.1 \%$ Formic acid

684 mixture for precipitating protein respectively. The samples were then vortexed for $30 \mathrm{~s}$.

685 After centrifugation at $4^{\circ} \mathrm{C}, 3900 \mathrm{rpm}$ for $15 \mathrm{~min}$, the supernatant was diluted 3 times

686 with water. $5 \mu \mathrm{L}$ of diluted supernatant was injected into the LC/MS/MS system (AB API

$6875500 \mathrm{LC} / \mathrm{MS} / \mathrm{MS}$ instrument with a Phenomenex Synergi $2.5 \mu \mathrm{m}$ Polar-RP $100 \mathrm{~A}(50 \times 3$

$688 \mathrm{~mm})$ column $)$ for quantitative analysis. The mobile phases used were $95 \%$ water $(0.1 \%$

689 formic acid) and $95 \%$ acetonitrile ( $0.1 \%$ formic acid). All PK studies were conducted by

690 Pharmaron in Ningbo, China.

691 Hamster Efficacy Studies. SARS-CoV-2 Isolate USA-WA1/ 2020 (NR-52281) was

692 provided by the Center for Disease Control and Prevention. SARS-CoV-2 was

693 propagated in Vero E6 cells in DMEM supplemented with 2\% FBS, 4.5 g/L D-glucose, 4

$694 \mathrm{mM}$ L-glutamine, $10 \mathrm{mM}$ Non-Essential Amino Acids, $1 \mathrm{mM}$ Sodium Pyruvate and 10

695 mM HEPES and filtered through an Amicon Ultracel $15(100 \mathrm{kDa})$ centrifugal filter. Flow

696 through was discarded and virus resuspended in DMEM supplemented as above.

697 Infectious titers of SARS-CoV-2 stock were determined using a plaque assay in Vero E6 
698 cells in Minimum Essential Media supplemented with 2\% FBS, 4 mM L-glutamine, 0.2\%

699 BSA, $10 \mathrm{mM}$ HEPES and $0.12 \% \mathrm{NaHCO} 3$ and $0.7 \%$ agar.

$700 \quad 3-5$ week-old Syrian hamsters were acclimated to the CDC/USDA-approved BSL-3

701 facility of the Global Health and Emerging Pathogens Institute at the Icahn School of

702 Medicine at Mount Sinai for 2-4 days. In our direct infection model, hamsters were given

703 a subcutaneous injection posteriorly with drug within 2 hours of drug (amodiaquine)

704 reconstitution one day before SARS-CoV-2 infection and every day thereafter until

705 terminal lung harvest on day 3 post infection. Amodiaquine was reconstituted in 12\%

706 sulfobutylether- $\beta$-cyclodextrin (Selleckchem) in water(w/w) (with $\mathrm{HCl} / \mathrm{NaOH})$ at $\mathrm{pH}$ 5.0.

707 Hamsters were intranasally infected with $10^{3}$ PFU of passage 3 SARS-CoV-2 USA-

708 WA1/2020 in $100 \mu$ of PBS and sacrificed on day 3 of infection. Animals were

709 anesthetized by intraperitoneal injection of $200 \mu \mathrm{l}$ of ketamine and xylazine (4:1) and

710 provided thermal support while unconscious. Whole lungs were harvested and

711 homogenized in $1 \mathrm{~mL}$ of PBS, and homogenates were then spun down at 10,000 rcf for

7125 minutes; the supernatant was subsequently discarded, and the lung pellet was

713 resuspended in Trizol. The same protocol was used in our animal-to-animal infection

714 model, except amodiaquine was administered to healthy hamsters for one day before

715 they were housed with untreated hamsters that were infected with SARS-CoV-2 one

716 day earlier, and drug continued to be administered daily for 3 more days, after which

717 infection transmission was quantified.

718 Lung RNA was extracted by phenol chloroform extraction and DNase treatment

719 using DNA-free DNA removal kit (Invitrogen). After cDNA synthesis of RNA samples by

720 reverse transcription using SuperScript II Reverse Transcriptase (invitrogen) with oligo 


\section{Confidential}

$721 \mathrm{~d}(\mathrm{~T})$ primers, quantitative RT-PCR was performed using KAPA SYBR FAST qPCR

722 Master Mix Kit (Kapa Biosystems) on a LightCycler 480 Instrument II (Roche) for

723 subgenomic nucleocapsid (N) RNA (sgRNA) and actin using the following primers: Actin

724 forward primer: 5'-CCAAGGCCAACCGTGAAAAG-3', Actin reverse primer 5'-

725 ATGGCTACGTACATGGCTGG-3', N sgRNA forward primer: 5'-

726 CTCTTGTAGATCTGTTCTCTAAACGAAC-3', N sgRNA reverse primer: 5'-

727 GGTCCACCAAACGTAATGCG-3' Relative sgRNA levels were quantified by

728 normalizing sgRNA to actin expression and normalizing drug-treated infected lung RNA

729 to vehicle-treated infected controls. All RNA Seq data utilized the Illumina TruSeq

730 Stranded mRNA LP as per the manufacturer's instructions. Illumina libraries were

731 quantified by Qbit and Agilent Bioanalyzer prior to being run on an Illumina NextSeq500

732 using a high capacity flow cell. All Raw data was processed as described elsewhere ${ }^{48}$.

733 Raw sequencing data files can be found on NCBI GEO (GSE143613).

734 Statistical analysis. All results presented are the result of at least two independent

735 experiments, and if not specified, at least three chips per donor were used in each

736 Organ Chip experiment. Tests for statistically significant differences between groups

737 were performed using a two-tailed Student's t-test and the Bonferroni correction for

738 multiple hypothesis testing. Differences were considered significant when the $P$ value

739 was less than $0.05\left({ }^{*}, P<0.05 ;{ }^{* *}, P<0.01 ;{ }^{* *}, P<0.001\right.$; n.s., not significant). All results

740 are expressed as means \pm standard deviation (SD); $\mathrm{N} \geq 3$ in all studies.

741 Data and materials availability. Sharing of materials will be subject to standard

742 material transfer agreements. The nucleotide sequences used in the study have been

743 deposited in GeneBank under accession numbers CY034139.1, CY0334138.1, 
X17336.1, HE802059.1, CY034135.1, CY034134.1, D10598.1, M12597.1, CY176949.1,

CY176948.1, CY176947.1, CY176942.1, CY176945.1, CY176944.1, CY176943.1, Supplementary Materials.

Contributors. L.S., H.B., and D.E.I. conceived this study, and D.E.I. developed the overall collaborative discovery pipeline. L.S. and H.B. performed and analyzed experiments with other authors assisting with experiments and data analysis. M.B. assisted with cytokine detection assay. W.C., C.O., A.J., A.N., and S.K. assisted with RNA extraction and qRT-PCR. D.Z. and G.G. assisted in the characterization of CoV2pp. R.K.P. assisted in statistical analysis. R.P. and S.E.G. coordinated experiments and managed the project progress. R.M., D.H., K.O., S.H., T.J., R.A.A. and B.R.t. tested the efficacy of amodiaquine against native SARS-CoV-2 in hamster SARS-CoV-2 infection model. K.C. coordinated the hamster PK studies and assisted in the design of dosing and drug formulation in the hamster efficacy studies. J.L., R.H., M.M., S.W., and M.F. tested the activity of amodiaquine and desethylamodiaquine against native SARS-

760 CoV-2 in Vero E6 cells. L.S., H.B. and D.E.I. wrote the manuscript with all authors 761 providing feedback.

Declaration of interests. D.E.I. is a founder and holds equity in Emulate Inc., and chairs its advisory board. D.E.I., L. S., R. P., H.B., K H. B., and M. R. are inventors on relevant patent applications hold by Harvard University.

Acknowledgements. We thank the CDC, Dr. A. Garcia-Sastre, Dr. R.A.M.

66 Fouchier, and Dr. X. Sealens for providing the influenza virus strains and the influenza 


\section{Confidential}

virus rescue systems. We acknowledge research funding from NIH (NCATS 1-UG3-HL141797-01 and NCATS 1-UH3-HL-141797-01 to D.E.I.), DARPA under Cooperative Agreements (W911NF-12-2-0036 to D.E.I. and W911NF-16-C-0050 to D.E.I., M.F., and B.tO.). Bill and Melinda Gates Foundation (to D.E.I. and M.F.), Marc Haas Foundation (to B.tO.), and the Wyss Institute for Biologically Inspired Engineering at Harvard University (D.E.I.).

Correspondence and requests for materials should be addressed to D.E.I., and to B.tO for issues related to hamster studies.

\section{REFERENCES}

1 Boulware, D. R. et al. A Randomized Trial of Hydroxychloroquine as Postexposure Prophylaxis for Covid-19. N Engl J Med, doi:10.1056/NEJMoa2016638 (2020).

2 Borba, M. G. S. et al. Effect of High vs Low Doses of Chloroquine Diphosphate as Adjunctive Therapy for Patients Hospitalized With Severe Acute Respiratory Syndrome Coronavirus 2 (SARS-CoV-2) Infection: A Randomized Clinical Trial. JAMA Netw Open 3, e208857, doi:10.1001/jamanetworkopen.2020.8857 (2020).

3 Hu, T. Y., Frieman, M. \& Wolfram, J. Insights from nanomedicine into chloroquine efficacy against COVID-19. Nature Nanotechnology, doi:10.1038/s41565-0200674-9 (2020).

4 Funnel, e. a. Emerging preclinical evidence does not support broad use of Hydroxychloroquine in COVID-19 patients. Nature Communications, doi:In Press (2020). 
7905 Huh, D. et al. Reconstituting organ-level lung functions on a chip. Science 328, 1662-1668, doi:10.1126/science.1188302 (2010).

7926 Huh, D. et al. A human disease model of drug toxicity-induced pulmonary edema 793 in a lung-on-a-chip microdevice. Sci Trans/ Med 4, 159ra147, doi:10.1126/scitransImed.3004249 (2012).

7957 Chou, D. B. et al. On-chip recapitulation of clinical bone marrow toxicities and 796 patient-specific pathophysiology. Nat Biomed Eng 4, 394-406, doi:10.1038/s41551-019-0495-z (2020).

8 Herland, A. et al. Quantitative prediction of human pharmacokinetic responses to 799 drugs via fluidically coupled vascularized organ chips. Nat Biomed Eng 4, 421436, doi:10.1038/s41551-019-0498-9 (2020).

80199 Prantil-Baun, R. et al. Physiologically Based Pharmacokinetic and Pharmacodynamic Analysis Enabled by Microfluidically Linked Organs-on-Chips. Annu Rev Pharmacol Toxicol 58, 37-64, doi:10.1146/annurev-pharmtox-010716104748 (2018).

Hui, K. P. Y. et al. Tropism, replication competence, and innate immune responses of influenza virus: an analysis of human airway organoids and ex-vivo bronchus cultures. Lancet Respir Med 6, 846-854, doi:10.1016/S22132600(18)30236-4 (2018). 


\section{Confidential}

81212 Chan, R. W., Chan, M. C., Nicholls, J. M. \& Malik Peiris, J. S. Use of ex vivo and

813 in vitro cultures of the human respiratory tract to study the tropism and host

814 responses of highly pathogenic avian influenza A (H5N1) and other influenza

$815 \quad$ viruses. Virus Res 178, 133-145, doi:10.1016/j.virusres.2013.03.003 (2013).

81613 Takayama, K. In Vitro and Animal Models for SARS-CoV-2 research. Trends

$817 \quad$ Pharmacol Sci 41, 513-517, doi:10.1016/j.tips.2020.05.005 (2020).

81814 Stojdl, D. F. et al. VSV strains with defects in their ability to shutdown innate 819 immunity are potent systemic anti-cancer agents. Cancer Cell 4, 263-275, 820 doi:10.1016/s1535-6108(03)00241-1 (2003).

$821 \quad 15$ Ainslie, G. R. et al. Microphysiological lung models to evaluate the safety of new 822 pharmaceutical modalities: a biopharmaceutical perspective. Lab Chip, doi:10.1039/c9lc00492k (2019).

82416 Benam, K. H. et al. Small airway-on-a-chip enables analysis of human lung 825 inflammation and drug responses in vitro. Nat Methods 13, 151-157, doi:10.1038/nmeth.3697 (2016). Disease. Cells 5, doi:10.3390/cells5040040 (2016). doi:10.1016/j.cell.2020.02.052 (2020).

83219 Sungnak, W. et al. SARS-CoV-2 entry factors are highly expressed in nasal epithelial cells together with innate immune genes. Nat Med 26, 681-687, doi:10.1038/s41591-020-0868-6 (2020). 


\section{Confidential}

83520 Armstrong, S. M., Mubareka, S. \& Lee, W. L. The lung microvascular

$836 \quad$ endothelium as a therapeutic target in severe influenza. Antiviral Res 99, 113-

$837 \quad$ 118, doi:10.1016/j.antiviral.2013.05.003 (2013).

83821 Cheung, C. Y. et al. Induction of proinflammatory cytokines in human

839 macrophages by influenza A (H5N1) viruses: a mechanism for the unusual

$840 \quad$ severity of human disease? Lancet $360,1831-1837$ (2002).

84122 Papayannopoulos, V. Neutrophil extracellular traps in immunity and disease. Nat

842 Rev Immunol 18, 134-147, doi:10.1038/nri.2017.105 (2018).

84323 Nicholson, K. G. et al. Efficacy and safety of oseltamivir in treatment of acute

844 influenza: a randomised controlled trial. Neuraminidase Inhibitor Flu Treatment

845 Investigator Group. Lancet 355, 1845-1850, doi:10.1016/s0140-6736(00)02288-1

$846 \quad(2000)$.

84724 Zhou, J. et al. Differentiated human airway organoids to assess infectivity of

$848 \quad$ emerging influenza virus. Proc Natl Acad Sci U S A 115, 6822-6827,

849 doi:10.1073/pnas.1806308115 (2018).

85025 Laporte, M. \& Naesens, L. Airway proteases: an emerging drug target for

851 influenza and other respiratory virus infections. Curr Opin Virol 24, 16-24,

852 doi:10.1016/j.coviro.2017.03.018 (2017).

85326 Simonson, W. Influenza treatment with antiviral medications. Geriatr Nurs 40, 99-

$854 \quad 100$, doi:10.1016/j.gerinurse.2018.12.007 (2019).

85527 Si, L. et al. Triterpenoids manipulate a broad range of virus-host fusion via

856 wrapping the HR2 domain prevalent in viral envelopes. Sci Adv 4, eaau8408,

857 doi:10.1126/sciadv.aau8408 (2018). 


\section{Confidential}

85828 Wu, F. et al. A new coronavirus associated with human respiratory disease in

859 China. Nature 579, 265-269, doi:10.1038/s41586-020-2008-3 (2020).

86029 Letko, M., Marzi, A. \& Munster, V. Functional assessment of cell entry and 861 receptor usage for SARS-CoV-2 and other lineage B betacoronaviruses. Nat Microbiol 5, 562-569, doi:10.1038/s41564-020-0688-y (2020).

$86330 \mathrm{Ou}, \mathrm{X}$. et al. Characterization of spike glycoprotein of SARS-CoV-2 on virus entry 864 and its immune cross-reactivity with SARS-CoV. Nat Commun 11, 1620, doi:10.1038/s41467-020-15562-9 (2020).

31 Johansen, L. M. et al. FDA-approved selective estrogen receptor modulators inhibit Ebola virus infection. Sci Transl Med 5, 190ra179, doi:10.1126/scitransImed.3005471 (2013).

32 Johansen, L. M. et al. A screen of approved drugs and molecular probes identifies therapeutics with anti-Ebola virus activity. Sci Transl Med 7, 290ra289, doi:10.1126/scitransImed.aaa5597 (2015).

33 Zhao, Y. et al. Toremifene interacts with and destabilizes the Ebola virus

$87434 \quad$ Hattermann, K. et al. Susceptibility of different eukaryotic cell lines to SARScoronavirus. Arch Virol 150, 1023-1031, doi:10.1007/s00705-004-0461-1 (2005).

87635 Matsuyama, S. et al. Enhanced isolation of SARS-CoV-2 by TMPRSS2expressing cells. Proc Natl Acad Sci U S A, doi:10.1073/pnas.2002589117 (2020).

87936 Chen Jun, L. Y., Xi Xiuhong, Liu Ping, Li Feng, Li Tao, Shang Zhiyin, Wang Mei, Shen Yinzhong, Lu Hongzhou. Efficacies of lopinavir/ritonavir and abidol in 


\section{Confidential}

881

882

883

884

885

886

887

888

889

890

891

892

893

894

895

896

897

898

899

900

901

902

903

the treatment of novel coronavirus pneumonia. Chin J Infect Dis 38, E008-E008, doi:10.3760/cma.j.cn311365-20200210-00050 (2020).

37 Orrell, C. et al. Pharmacokinetics and tolerability of artesunate and amodiaquine alone and in combination in healthy volunteers. Eur J Clin Pharmacol 64, 683690, doi:10.1007/s00228-007-0452-8 (2008).

38 Ingber, D. E. Is it time for reviewer 3 to request human organ chip experiments instead of animal validation studies? Advanced Science, doi:In Press (2020).

39 Marx, U. et al. Biology-inspired microphysiological systems to advance patient benefit and animal welfare in drug development. ALTEX, doi:10.14573/altex.2001241 (2020).

40 Li, Y. et al. Efficacy and safety of lopinavir/ritonavir or arbidol in adult patients with mild/moderate COVID-19: an exploratory randomized controlled trial. Med, doi:10.1016/j.medj.2020.04.001.

41 Jeon, S. et al. Identification of antiviral drug candidates against SARS-CoV-2 from FDA-approved drugs. Antimicrob Agents Chemother, doi:10.1128/AAC.00819-20 (2020).

42 Weston, S., Haupt, R., Logue, J., Matthews, K. \& Frieman, M. B. FDA approved drugs with broad anti-coronaviral activity inhibit SARS-CoV-2 <em>in vitro</em>. bioRxiv, 2020.2003.2025.008482, doi:10.1101/2020.03.25.008482 (2020).

43 DeWald, L. E. et al. In Vivo Activity of Amodiaquine against Ebola Virus Infection. Sci Rep 9, 20199, doi:10.1038/s41598-019-56481-0 (2019).

44 Sinou, V. et al. Pharmacokinetics and pharmacodynamics of a new ACT formulation: Artesunate/Amodiaquine (TRIMALACT) following oral administration 


\section{Confidential}

904

905

906

907

908

909

910

911

912

913

914

915

916

917

918

in African malaria patients. Eur J Drug Metab Pharmacokinet 34, 133-142, doi:10.1007/BF03191163 (2009).

45 Gignoux, E. et al. Effect of Artesunate-Amodiaquine on Mortality Related to Ebola Virus Disease. N Engl J Med 374, 23-32, doi:10.1056/NEJMoa1504605 (2016).

46 CDC. International Notes Agranulocytosis Associated with the Use of Amodiaquine for Malaria Prophylaxis. MMWR 35, 165-166 (1986).

47 Hou, Y. J. et al. SARS-CoV-2 Reverse Genetics Reveals a Variable Infection Gradient in the Respiratory Tract. Cell 182, 429-446 e414, doi:10.1016/j.cell.2020.05.042 (2020).

48 Blanco-Melo, D. et al. Imbalanced Host Response to SARS-CoV-2 Drives Development of COVID-19. Cell 181, 1036-1045 e1039, doi:10.1016/j.cell.2020.04.026 (2020). 
a

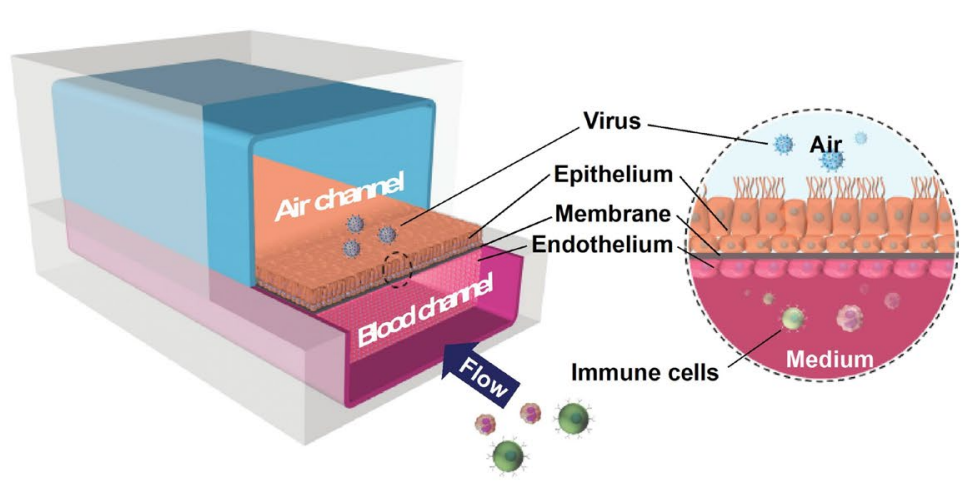

b

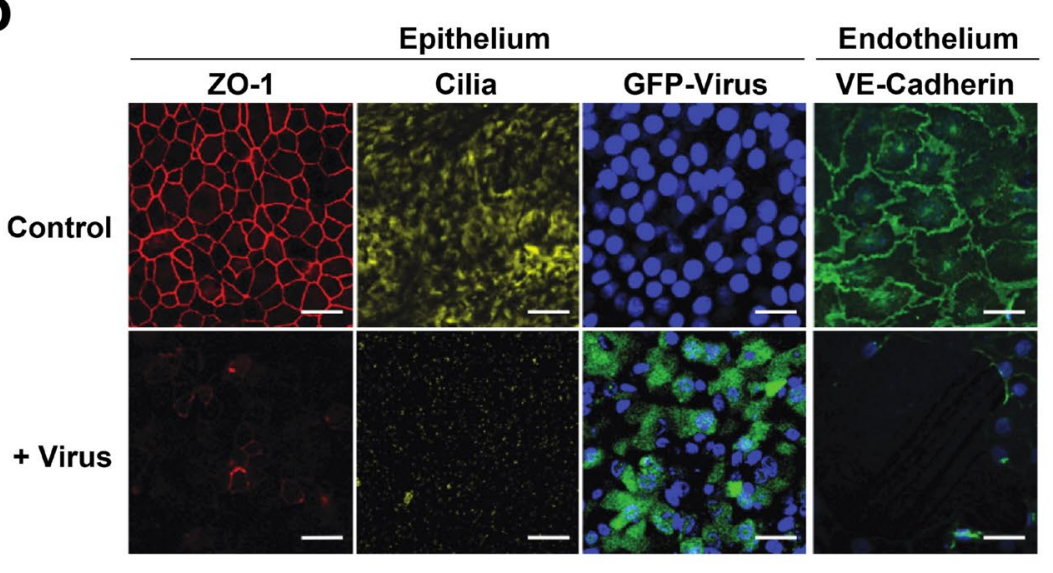

d

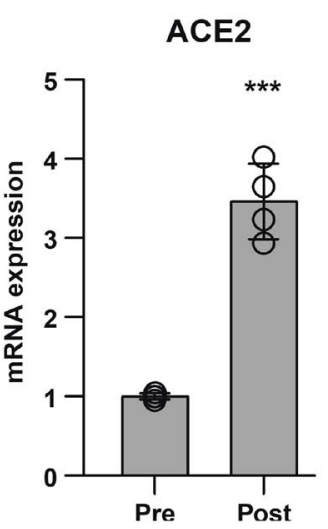

e

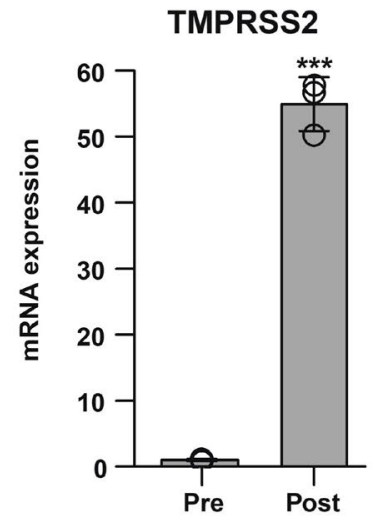

C Lung Airway Epithelial Cell ACE2 Expression

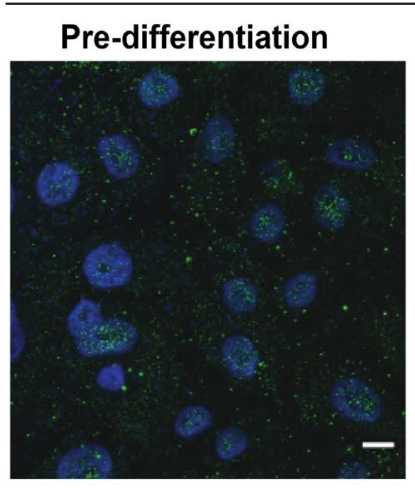

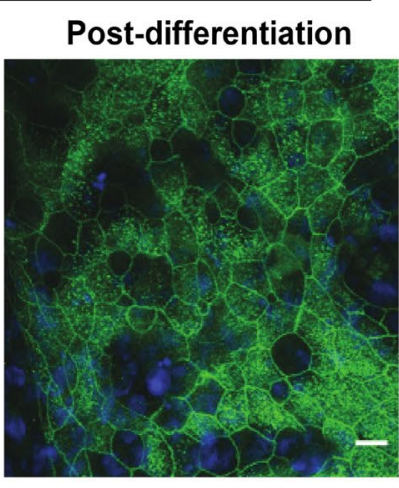

$\mathbf{f}$

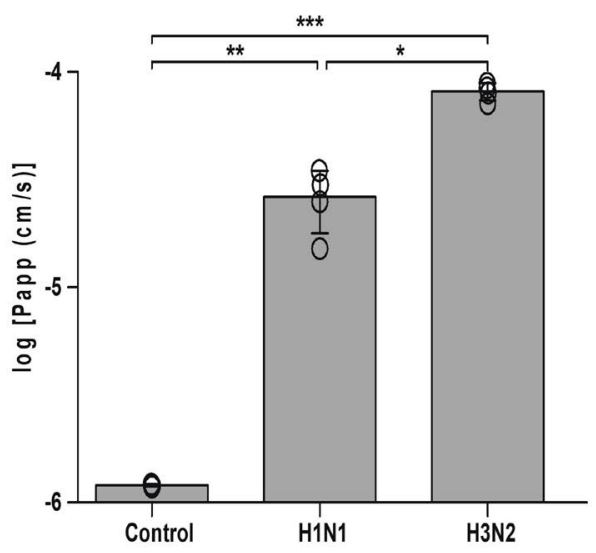

Fig. 1. Characterization of the human Airway Chip and its infection with 


\section{Confidential}

924 junctions and cilia in the epithelium and VE-cadherin-containing adherens junctions in

925 the endothelium of the Airway Chip in the absence (Control) or presence (+ Virus) of

926 infection with GFP-labeled influenza PR8 $(\mathrm{H} 1 \mathrm{~N} 1)$ virus $(\mathrm{MOI}=0.1)$ for $48 \mathrm{~h}$ (blue, DAPI-

927 stained nuclei; bar, $50 \mu \mathrm{m}$ ). (c-e) Immunofluorescence micrographs showing the

928 expression of ACE2 receptor (c) and fold changes in mRNA levels of ACE2 (d) and

929 TMPRSS2 (e) in the well-differentiated primary human lung airway epithelim on-chip

930 (Post) versus the same cells prior to differentiation (Pre). (f) Increase in barrier

931 permeability as measured by apparent permeability $\left(\log P_{a p p}\right)$ within the human Airway

932 chip $48 \mathrm{~h}$ post-infection with PR8 $(\mathrm{H} 1 \mathrm{~N} 1)$ or $\mathrm{HK} / 68(\mathrm{H} 3 \mathrm{~N} 2)$ virus $(\mathrm{MOI}=0.1)$ compared

933 to no infection (Control). 


\section{Confidential}

a

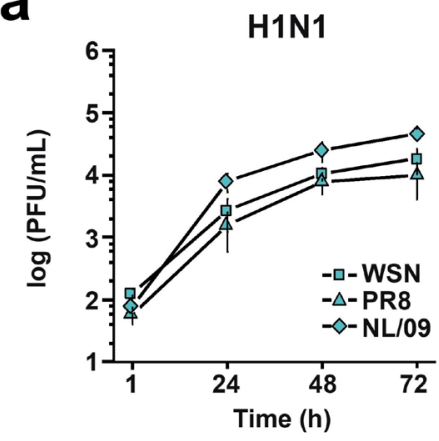

C

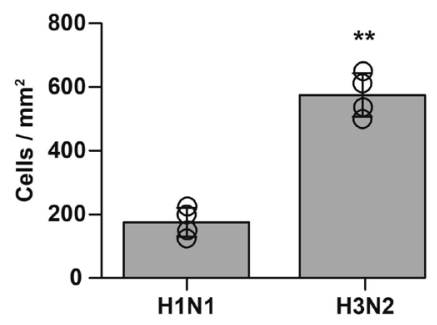

e

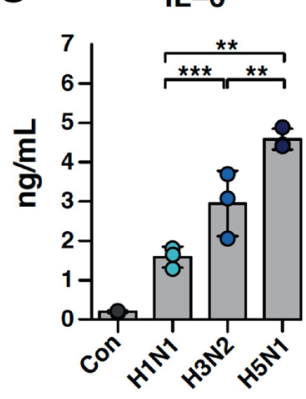

IP-10

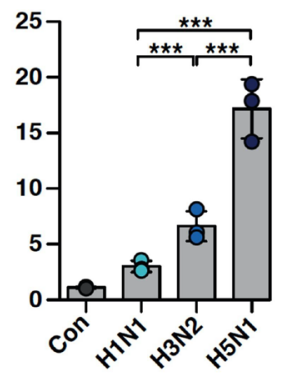

H3N2

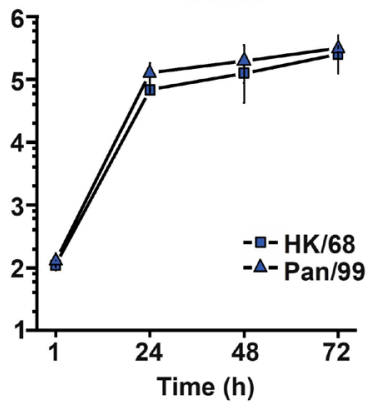

b
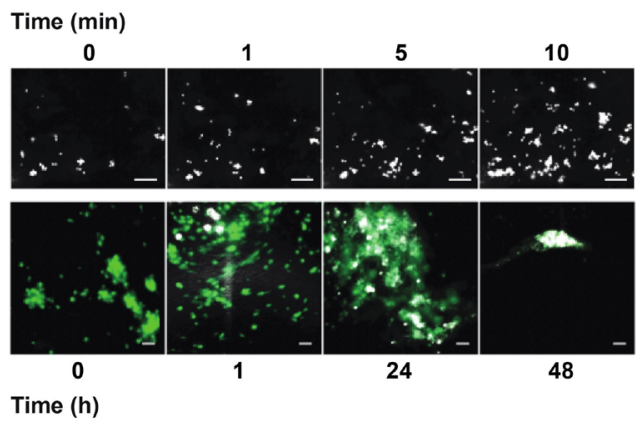

d
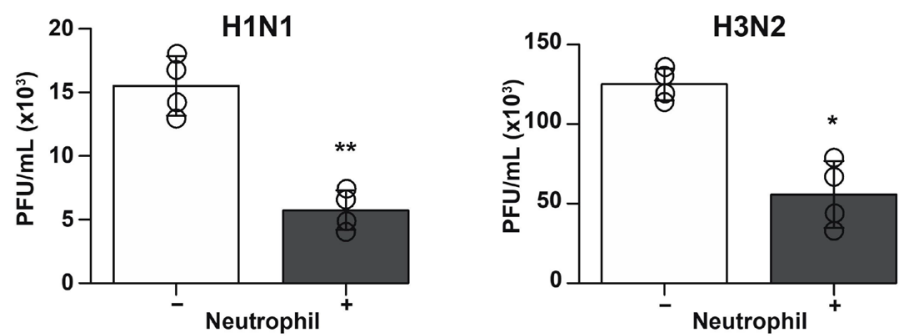

Fig. 2. Infection with multiple influenza strains in human Airway Chips and

resultant immune responses. (a) Replication kinetics of influenza H1N1 virus strains

WSN (square), PR8 (triangle), NL/09 (diamond) (left graph), and of influenza H3N2

virus strains HK/68 (square) and Pan/99 (triangle) (right graph), when infected at $\mathrm{MOI}=$

(b) Neutrophil responses to influenza infection in human

941 lung Airway Chip. Top, sequential immunofluorescence micrographs showing timedependent recruitment of neutrophils (white) to the apical surface of the endothelium

943 (unlabeled) within a human Airway Chip infected with influenza PR8 (H1N1) virus (bar, $50 \mu \mathrm{m})$. Bottom, immunofluorescence micrographs showing time-dependent recruitment 


\section{Confidential}

945 of neutrophils (white) to the epithelium (unlabeled) and clearance of clustered epithelial

946 cells infected with GFP-labeled PR8 (H1N1) virus (green) (bar, $50 \mu \mathrm{m})$. (c) Graph

947 showing numbers of neutrophils recruited to the epithelium in response to infection by

948 H1N1 or H3N2. (d) Virus titers of human Airway Chips infected with WSN (H1N1) or

$949 \quad \mathrm{HK} / 68(\mathrm{H} 3 \mathrm{~N} 2)$ in the presence $(+)$ or absence $(-)$ of added neutrophils (PFU, plaque-

950 forming units). (e) Production of indicated cytokines and chemokines in the human

951 Airway chip at $48 \mathrm{~h}$ post-infection with different clinically isolated influenza virus strains,

952 including NL/09 (H1N1), Pan/99 (H3N2), and HK/97 (H5N1) (MOI = 0.1). *, P<0. 05; **,

$953 \quad \mathrm{P}<0.01 ;{ }^{* * *}, \mathrm{P}<0.001$.

954 


\section{Confidential}

a

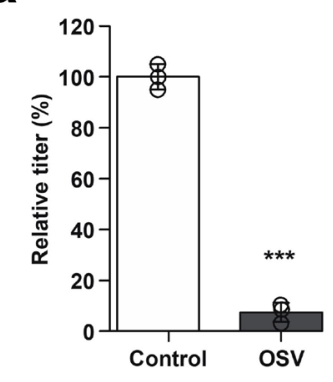

d

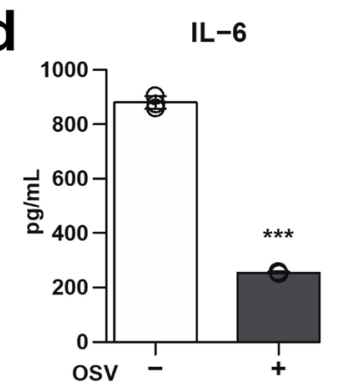

b

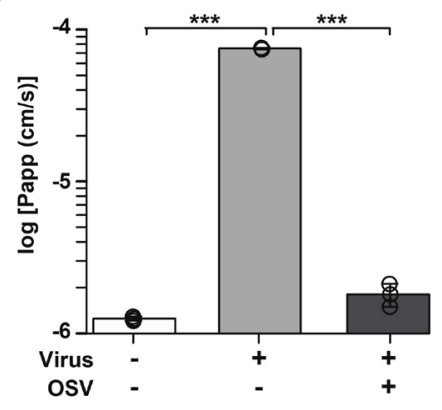

C

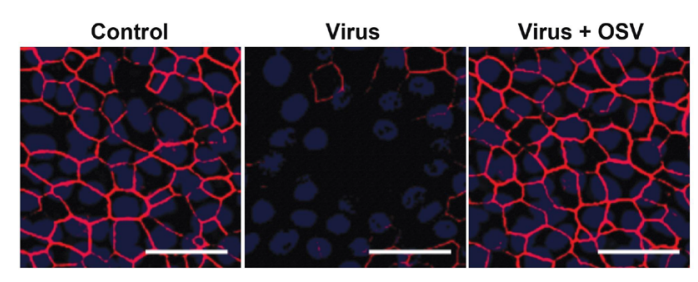

e

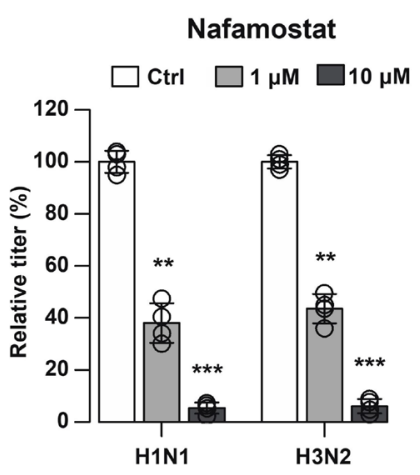

IP-10

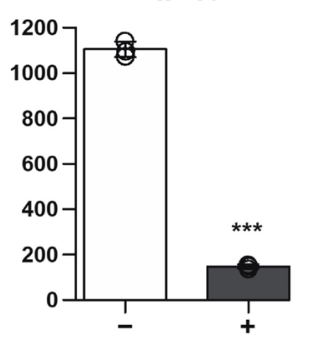

RANTES

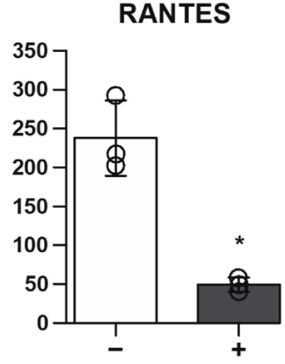

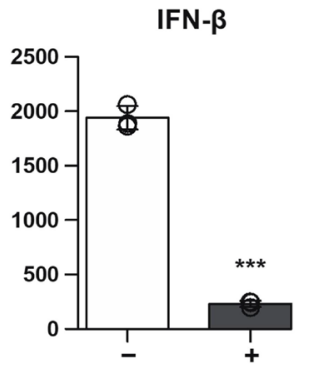

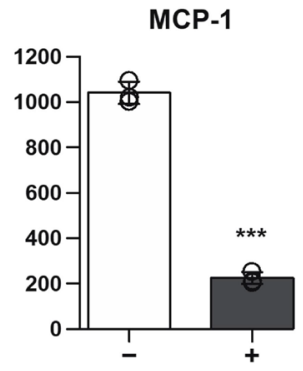

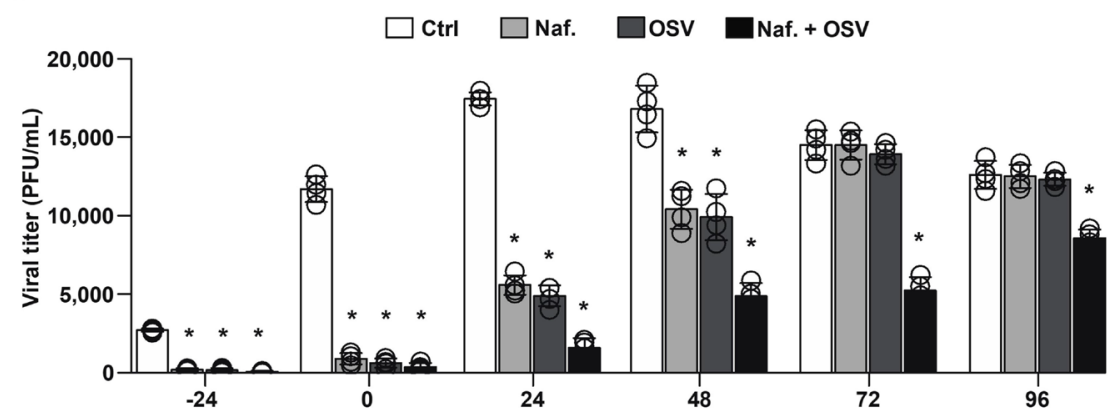

Fig. 3. Effects of anti-influenza therapeutics in the human Airway Chip. (a)

Graph showing relative plaque titers of progeny virus in the absence (Ctrl) or presence 


\section{Confidential}

964 (d) Production of cytokines in human Airway Chip $48 \mathrm{~h}$ post-infection with WSN in the 965 presence (+) or absence (-) of OSV. (e) Virus titer detection showing the effects of

966 Nafamostat at $1 \mu \mathrm{M}$ (grey bars) or $10 \mu \mathrm{M}$ (white bars) dose on virus replication of H1N1 967 and H3N2 in Airway chips $48 \mathrm{~h}$ post-infection compared to untreated chips (Ctrl, black

968 bars). (f) The effects of Nafamostat, oseltamivir and their combination on relative viral 969 titers when added to H1N1 virus-infected human Airway Chips at indicated times; note

970 the synergistic effects of these two drugs at later times. ${ }^{*}, \mathrm{P}<0.05 ;{ }^{* *}, \mathrm{P}<0.01 ;{ }^{* * *}$, $971 \quad \mathrm{P}<0.001$. 
a

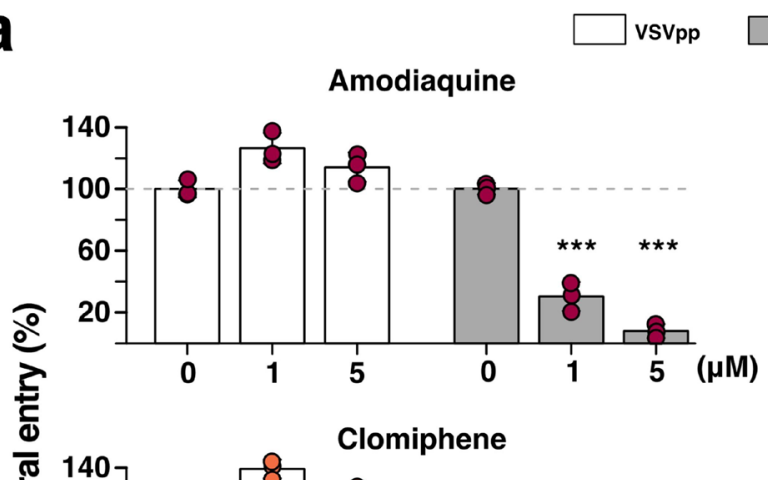

SARS-CoV-2pp
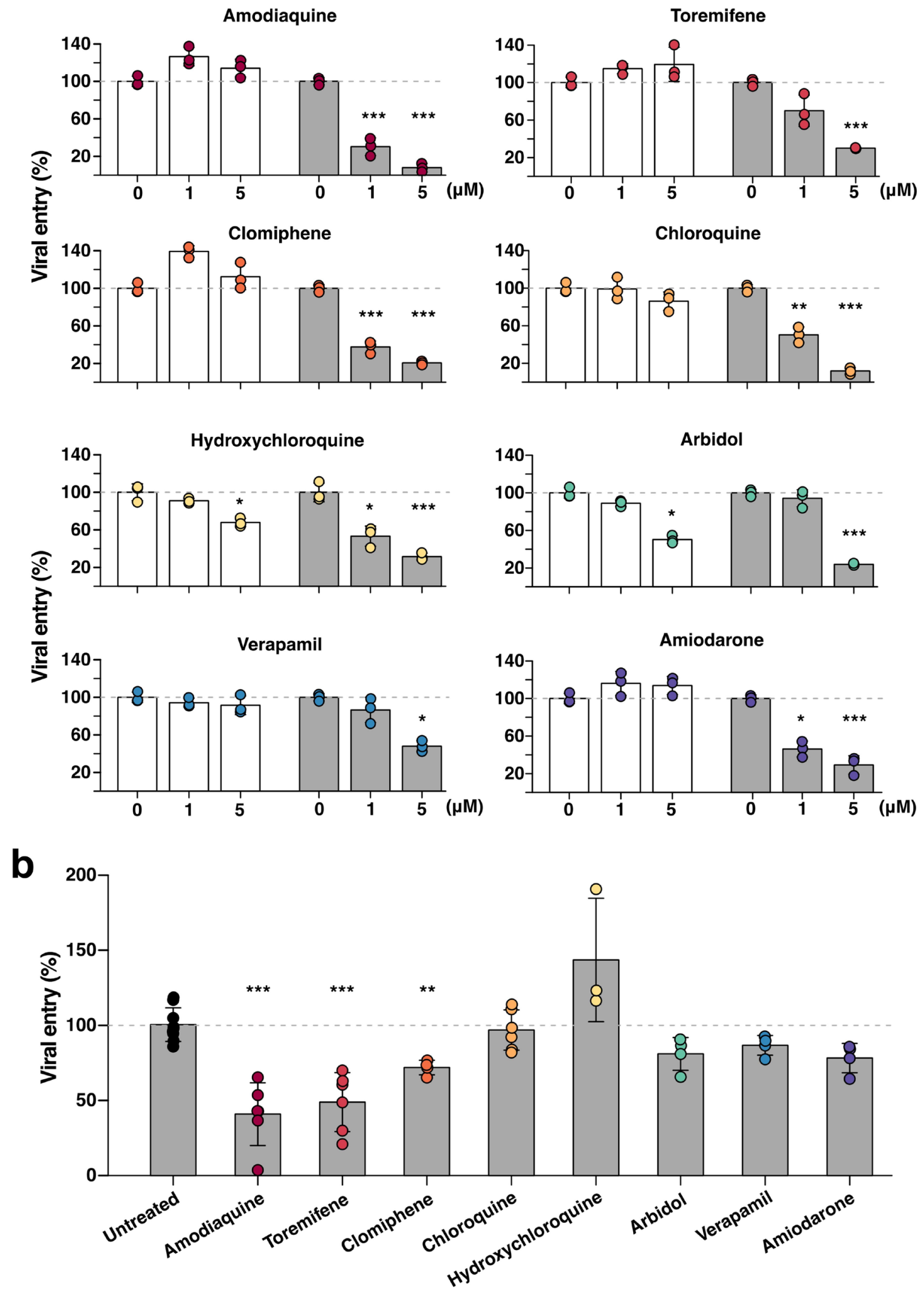


\section{Confidential}

\section{Fig. 4. Effects of FDA-approved drugs on pseudotyped SARS-CoV-2 viral} entry in Huh-7 cells versus human Airway Chips. (a) Graphs showing the inhibitory effects of amodiaquine, toremifene, clomiphene, chloroquine, hydroxychloroquine, arbidol, verapamil, and amiodarone when added at 0,1 , or $5 \mu \mathrm{M}$ to Huh-7 cells infected with SARS-CoV-2pp for $72 \mathrm{~h}$ (grey bars). The number of pseudoparticles in the infected cells was quantified by measuring luciferase activity; viral entry in untreated cells was set as $100 \%$. VSVpp were tested in parallel to exclude toxic and nonspecific effects of the drugs tested (white bars). (b) The efficacy of the same drugs in human Airway Chips infected with SARS-CoV-2pp. Amodiaquine, toremifene, clomiphene, chloroquine, hydroxychloroquine, arbidol, verapamil, and amiodarone were delivered into apical and basal channels of the chip at their respective $C_{\max }$ in human blood, and one day later chips were infected with SARS-CoV-2pp while in the continued presence of the drugs for 2 more days. The epithelium from the chips were collected for detection of viral pol gene by qRT-PCR; viral entry in untreated chips was set as $100 \%$. *, $\mathrm{P}<0.05$; **, $\mathrm{P}<$ $0.01 ;{ }^{* *}, \mathrm{P}<0.001$. 
a
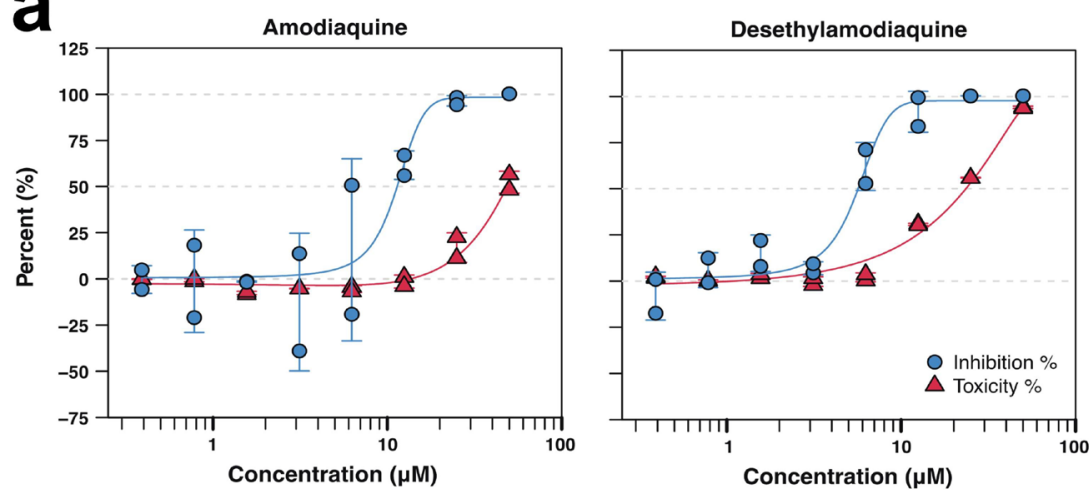

C

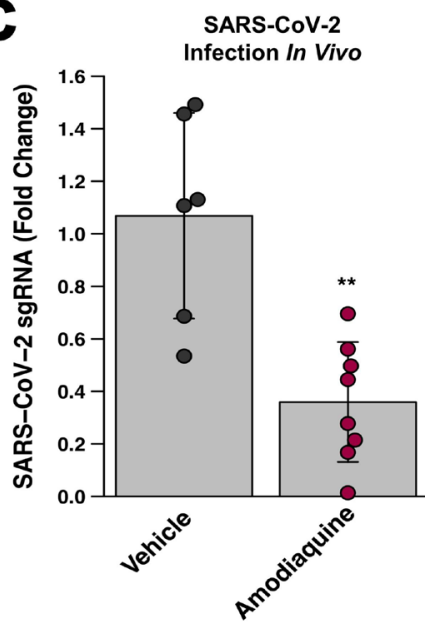

1

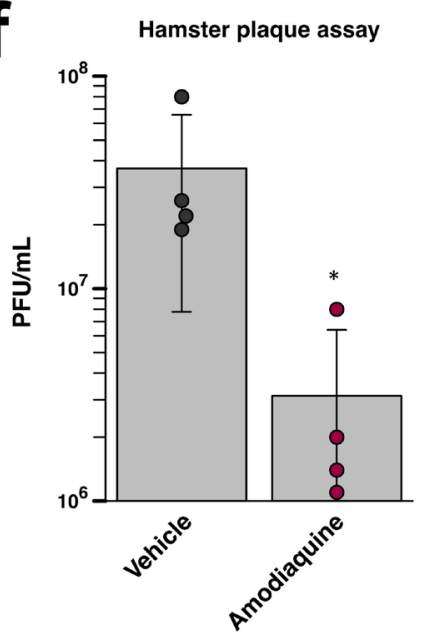

d

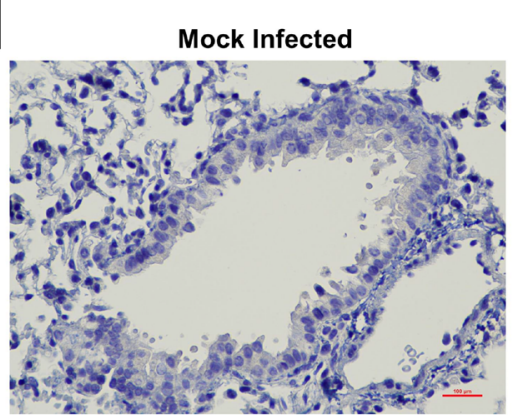

Vehicle + SARS-CoV-2
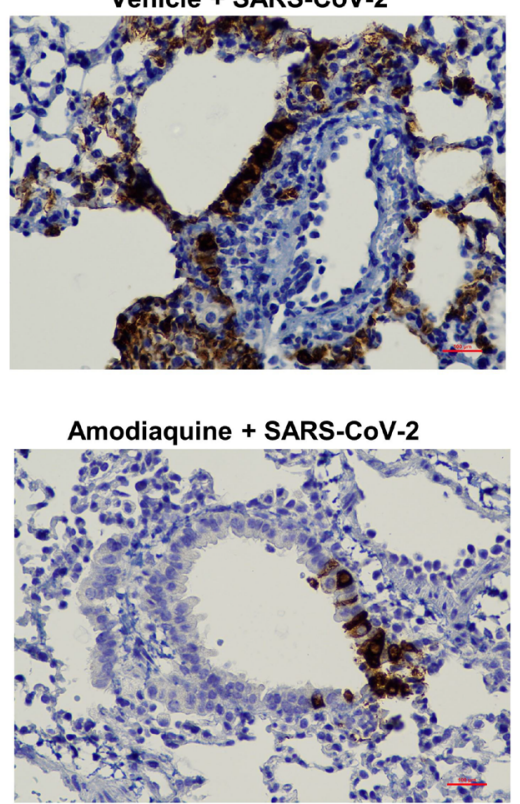

b

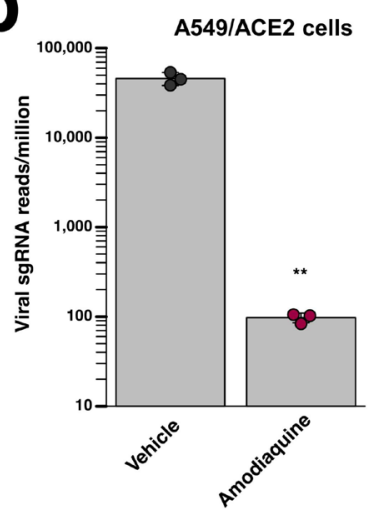

e

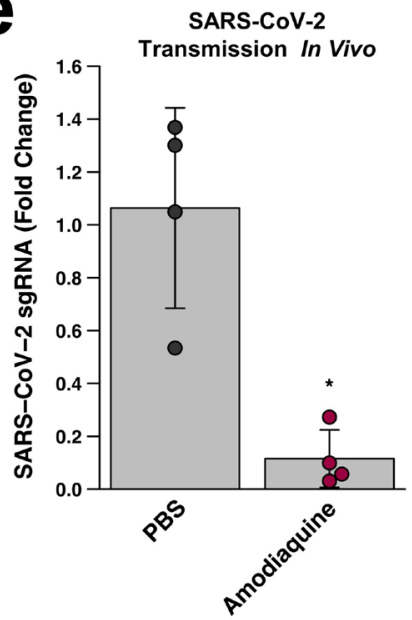

988

Fig. 5. Inhibition of infection by native SARS-CoV-2 virus in vitro and in vivo.

(a) Dose-response curves for amodiaquine and its metabolite desethylamodiaquine demonstrating their ability to inhibit GFP-SARS-CoV-2 infection $(\mathrm{MOI}=0.1)$ in a dose- 


\section{Confidential}

992 dependent manner in Vero E6 cells. (b) Inhibition of wild type SARS-CoV-2 infection in

993 ACE2-expressing A549 cells by $10 \mu \mathrm{M}$ amodiaquine. (c) Reduction of viral load in the

994 lungs of hamsters treated once a day with amodiaquine $(50 \mathrm{mg} / \mathrm{kg})$ beginning 1 day

995 prior to intranasal administration of SARS-CoV-2 virus ( $10^{3}$ PFU) as measured by qPCR

996 for subgenomic RNA encoding SARS-CoV-2 N protein. ${ }^{* *}, p<0.01$. (d) Hematoxylin-

997 and SARS-CoV-2 N-stained histological sections of lungs from animals that were mock

998 treated, infected with SARS-CoV-2 and treated with vehicle alone, or infected with

999 SARS-CoV-2 and treated with amodiaquine (50 mg/kg subcutaneously). (e) Reduction

1000 of viral load in the lungs of hamsters treated once a day for 4 days with amodiaquine

1001 (50 mg/kg) beginning 1 day prior to co-caging with SARS-CoV-2 infected animals as

1002 measured by qPCR for RNA encoding SARS-CoV-2 N protein. * $p<0.05$. (f) Graph

1003 depicting plaque forming units (PFU) per $\mathrm{mL}$ of lung homogenate from hamsters

1004 pretreated with vehicle or amodiaquine one day prior to being exposed to infected

1005 animals. Each cohort was comprised of 4 animals; $p$-value $=0.037$.

1006

1007 Table 1. Clinically relevant drug concentrations used in human Airway Chips.

\begin{tabular}{|c|c|c|}
\hline Drug & $\mathrm{C}_{\max }(\mathrm{ng} / \mathrm{ml})$ & $\mathrm{C}_{\max }(\mu \mathrm{M})$ \\
\hline Amodiaquine & 575 & 1.24 \\
\hline Toremifene & 1211 & 2.98 \\
\hline Clomiphene & 500 & 0.83 \\
\hline Chloroquine & 960.5 & 1.91 \\
\hline Hydroxychloroquine & 422 & 1.25 \\
\hline Arbidol & 2160 & 3.89 \\
\hline Verapamil & $287 \pm 105$ & 0.81 \\
\hline Amiodarone & $13660 \pm 3410$ & 20.04 \\
\hline Desethylamodiaquine & $329-828$ & 1.00 \\
\hline
\end{tabular}


a

\begin{tabular}{cccc}
\hline Cell type & $\begin{array}{c}\text { Current } \\
\text { Airway Chip }\end{array}$ & $\begin{array}{c}\text { Human } \\
\text { Airway }\end{array}$ & $\begin{array}{c}\text { Published } \\
\text { Airway Chip }\end{array}$ \\
\hline Ciliated cell (\%) & $\sim 60-80$ & $\sim 50-70$ & $\sim 20-30$ \\
Goblet cell (\%) & $\sim 10-15$ & $\sim 10-15$ & $\sim 10-20$ \\
Club cell (\%) & $\sim 15-20$ & $\sim 11-44$ & $\sim 25$ \\
Basal cell (\%) & $\sim 10-20$ & $\sim 6-30$ & $\sim 20$ \\
\hline
\end{tabular}

b
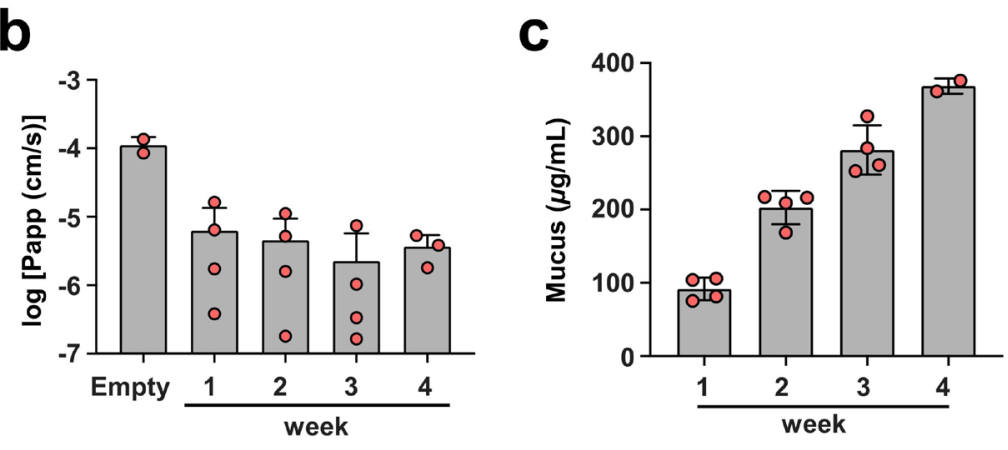

d

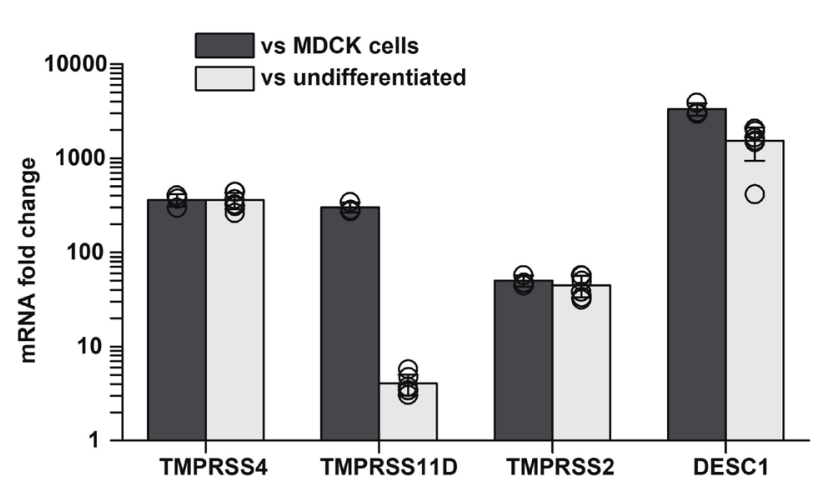

1012 of the percentage of different lung epithelial cell types in the human Airway Chip

1013 presented here compared with those found in living human airway and in our previously

1014 published Airway Chip created using a membrane with smaller pores ${ }^{6,7}$. (b) Barrier

1015 permeability (log Papp) of the human Airway Chip assessed using Cascade blue (607

$1016 \mathrm{Da}$ ) as fluorescent tracer at 1 to 4 weeks of differentiation under an ALI compared with

1017 chips without cells (Empty). (c) Mucus production at week 1, 2, 3, and 4 post- 


\section{Confidential}

1018 differentiation quantified using an Alcian Blue assay. (d) Fold changes in gene

1019 expression levels of 4 different epithelial cell serine proteases (TMPRSS4,

1020 TMPRSS11D, TMPRSS2, DESC1) in the well-differentiated Airway Chip versus MDCK

1021 cells (one of the most commonly used cell lines in influenza studies) or undifferentiated 1022 primary human lung airway epithelial cells. 
a

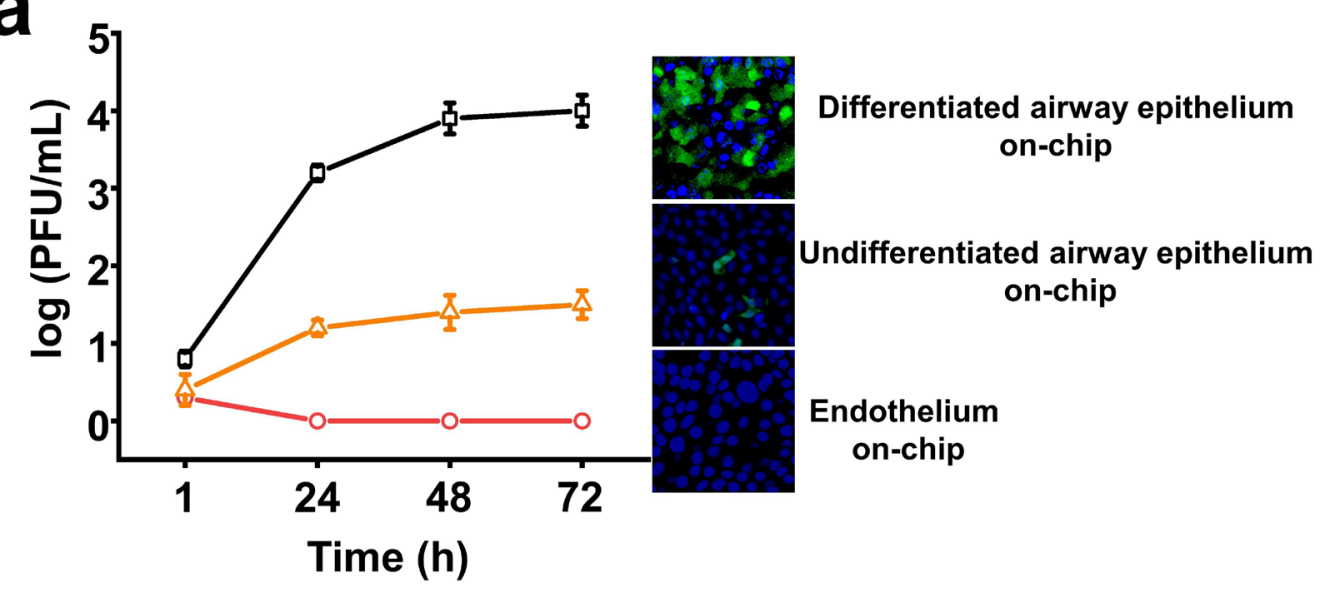

b

Ctrl

H1N1

H3N2
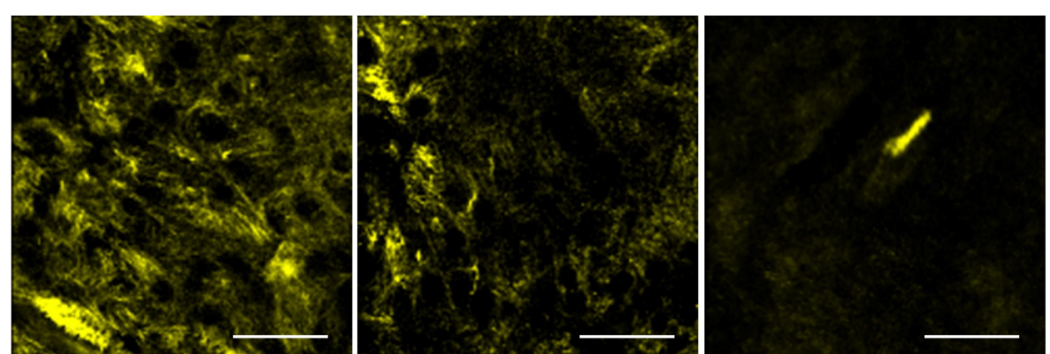

C.

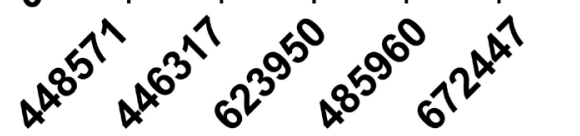

\begin{tabular}{cccc}
\hline Donor \# & Gender & Age & Health status \\
\hline 448571 & Male & 28 & Healthy \\
446317 & Male & 67 & Healthy \\
623950 & Male & 60 & Healthy \\
485960 & Male & 38 & Healthy \\
672447 & Female & 73 & Healthy \\
\hline
\end{tabular}

Extended Data Fig. 2. (a) Comparison of infectivity and replication of GFP-labeled

1025 PR8 (H1N1) in the differentiated epithelium of human lung Airway chip, undifferentiated 1026 airway epithelium on-chip, and human vascular endothelium on-chip. Graph showing

1027 replication kinetics of influenza PR8 $(\mathrm{H} 1 \mathrm{~N} 1)$ virus $(\mathrm{MOI}=0.001)$ in differentiated 


\section{Confidential}

1028 epithelium of human Airway Chip, undifferentiated epithelium on-chip, and human

1029 vascular endothelium on-chip (left) and corresponding immunofluorescence

1030 micrographs showing the infection of GFP-labeled PR8 $(\mathrm{H} 1 \mathrm{~N} 1)$ virus $(\mathrm{MOI}=0.1)$ in

1031 these respective chips at $48 \mathrm{~h}$ post-infection (green, cells expressing GFP-labeled virus;

1032 blue, DAPI-stained nuclei). (b) Immunofluorescence micrographs showing apical cilia 24

1033 h post-infection with PR8 $(\mathrm{H} 1 \mathrm{~N} 1)$ or HK/68 $(\mathrm{H} 3 \mathrm{~N} 2)(\mathrm{MOI}=0.1)$ compared to untreated

1034 chips (Ctrl). (c) Characterization of the replication competence of influenza virus in

1035 human lung Airway Chips created with lung airway epithelial basal stem cells obtained

1036 from 5 different healthy donors. Influenza PR8 (H1N1) virus was used to infect human

1037 Airway chips $(\mathrm{MOI}=0.1)$, and progeny viruses were collected for viral titers detection 48

$1038 \mathrm{~h}$ later. Information on the donors is shown in the table at the right. 


\section{Confidential}

1040

H1N1

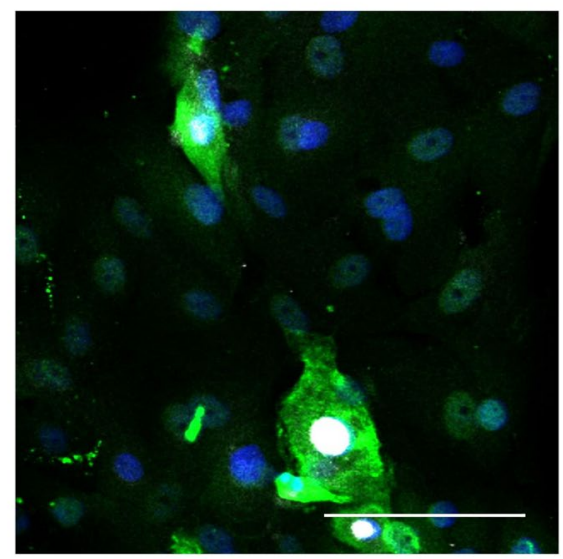

H3N2

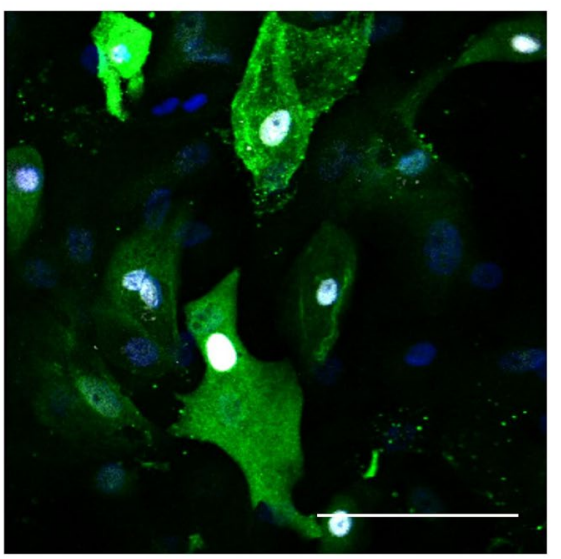

1041

1042

1043 showing specific binding of neutrophils (white) to cells infected by WSN (H1N1) or

$1044 \quad H K / 68$ (H3N2), which are stained for viral NP (green) (bar, $50 \mu \mathrm{m})$. 


\section{Confidential}
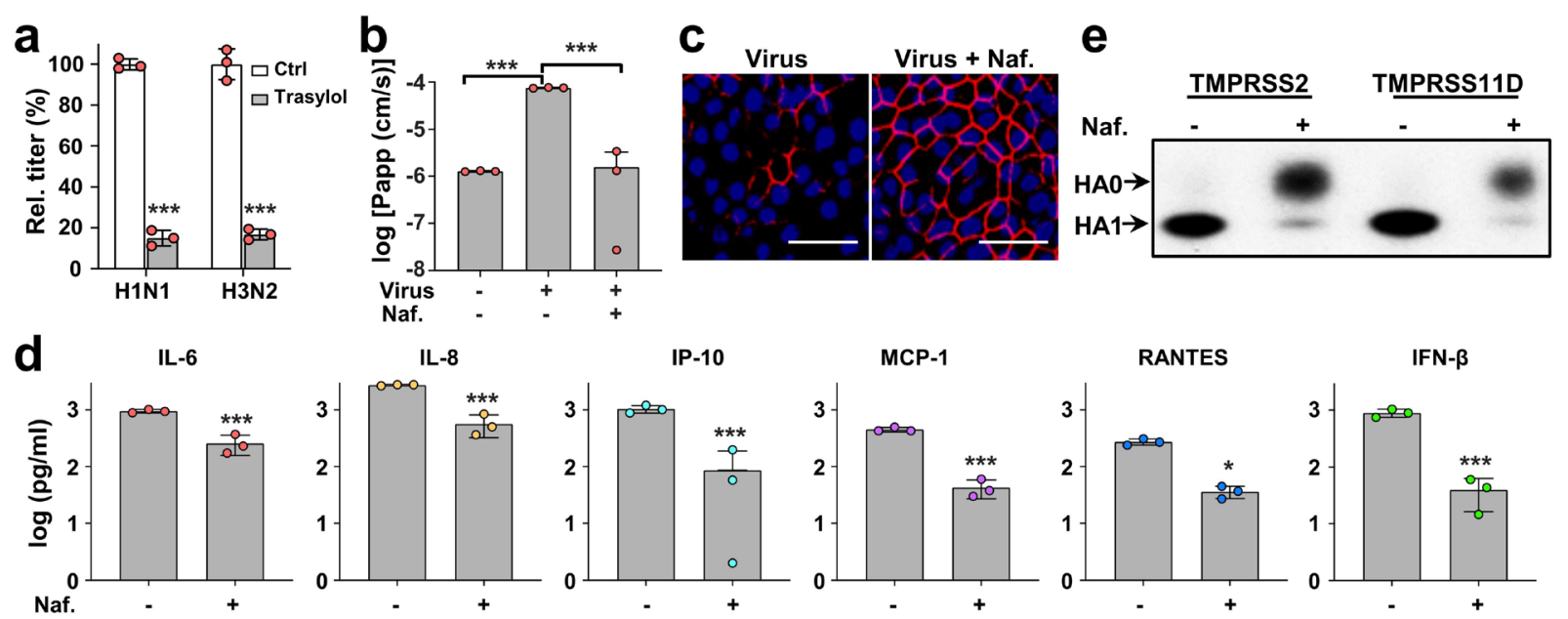

Extended Data Fig. 4. Characterization of FDA-approved protease inhibitor

drugs as anti-influenza therapeutics in the human lung Airway Chip. (a) Virus titer detection showing the effects of Trasylol (aprotinin) on virus replication of $\mathrm{H} 1 \mathrm{~N} 1$ and H3N2 in Airway chips $48 \mathrm{~h}$ post-infection (Trasylol, gray bars) compared to untreated chips (Ctrl, white bars). (b) Barrier permeability (log $P_{a p p}$ ) within human Airway Chips measured $48 \mathrm{~h}$ post-infection with $\mathrm{H} 1 \mathrm{~N} 1$ (MOI = 0.1) (+ Virus) in the presence $(+)$ or absence (-) of $10 \mu \mathrm{M}$ Nafamostat (Naf.) compared to uninfected chips (- Virus). (c) Immunofluorescence micrographs showing preservation of ZO1-containing tight junctions seen that are lost in airway epithelium $48 \mathrm{~h}$ after infection with $\mathrm{H} 1 \mathrm{~N} 1$ (MOI = Production of various influenza-associated cytokines and chemokines in the human Airway Chip in the presence (+) or absence (-) of $10 \mu \mathrm{M}$ Nafamostat (Naf.), which suppresses the cytokine response. (e) Western blots showing inhibition of TMPRSS2and TMPRSS11D-mediated cleavage of influenza virus HA0 to HA1 by $10 \mu \mathrm{M}$ Nafamostat (Naf.). 


\section{Confidential}

a

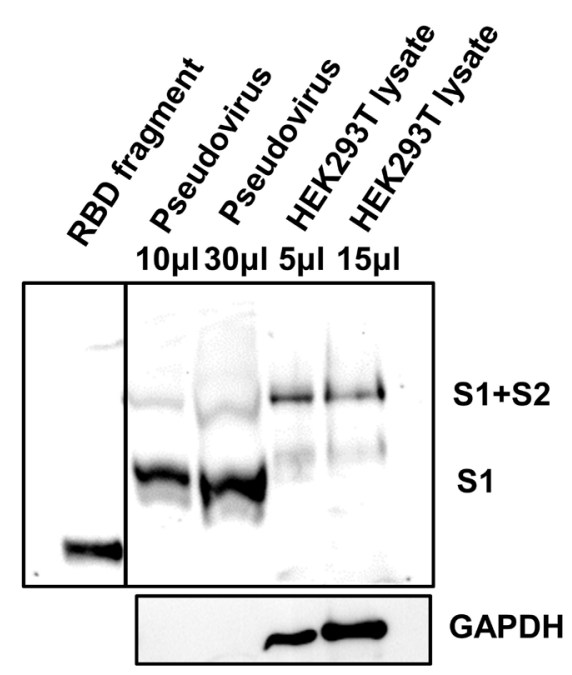

b

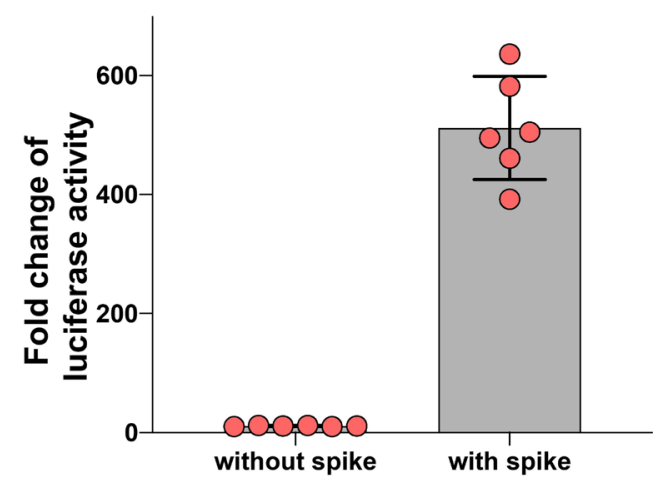
HEK293T packaging cell line and in pseudotyped virions in the supernatant showing that both uncleaved full-length $(\mathrm{S} 1+\mathrm{S} 2 ; \sim 180 \mathrm{kDa})$ and cleaved forms $(\sim 90 \mathrm{kDa})$ of the spike protein are present in the virions. A recombinant protein containing the receptor binding region domain from S1 (RBD fragment) was used as a positive control, and results were compared to cellular GAPDH. (b) Huh-7 cells were infected with SARSCoV-2pp for $72 \mathrm{~h}$. Luciferase activity was measured to estimate the number of pseudoparticles in the host cells; pseudoparticles without SARS-CoV-2 spike protein were used as control. 


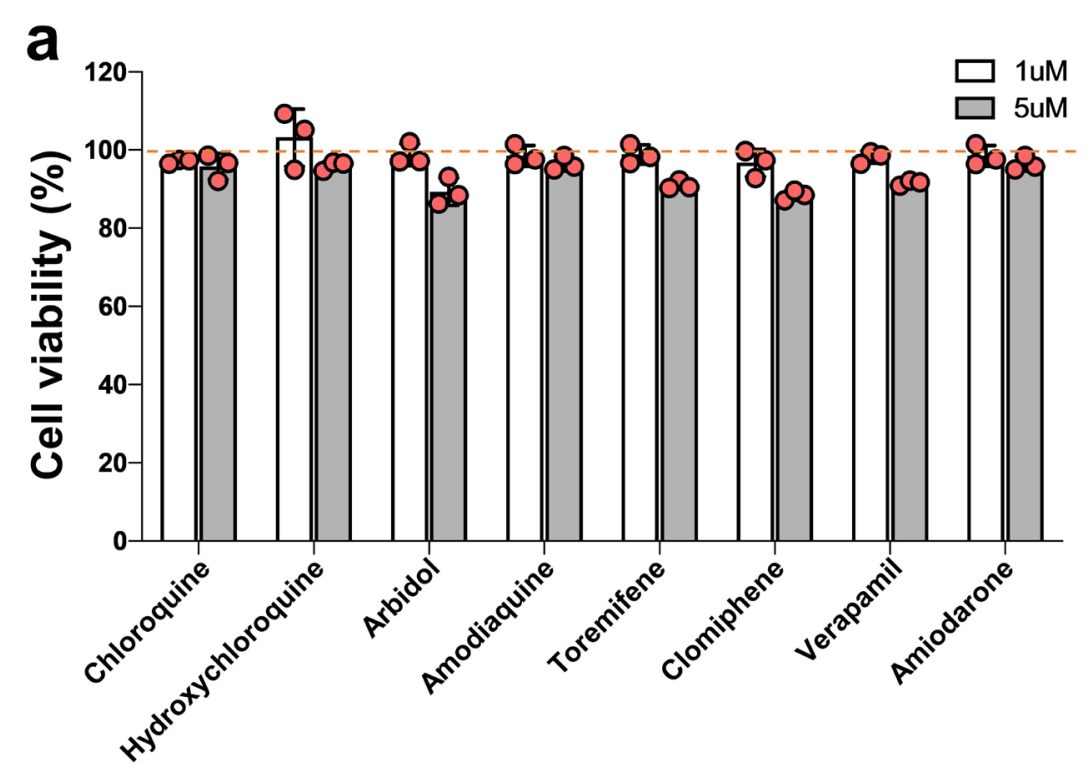

b

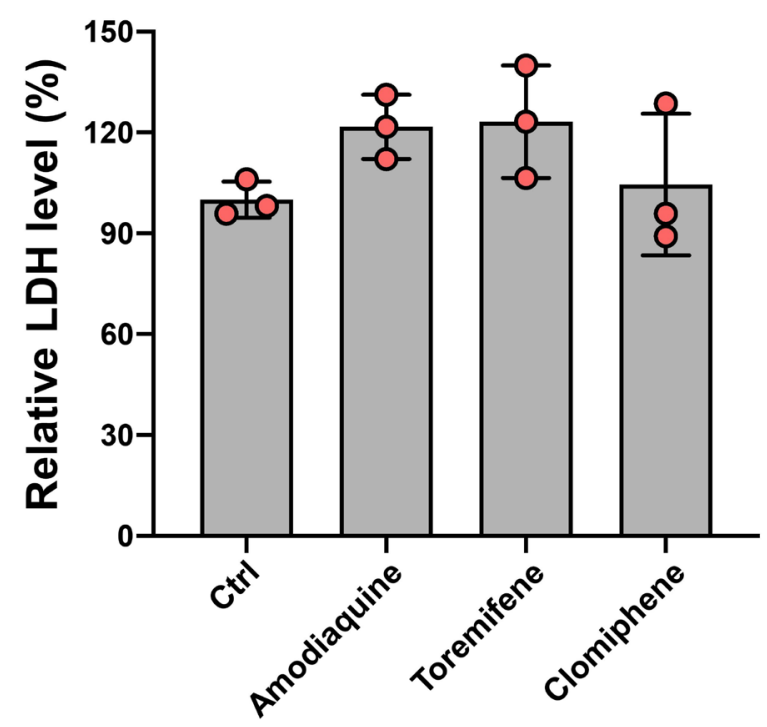


a

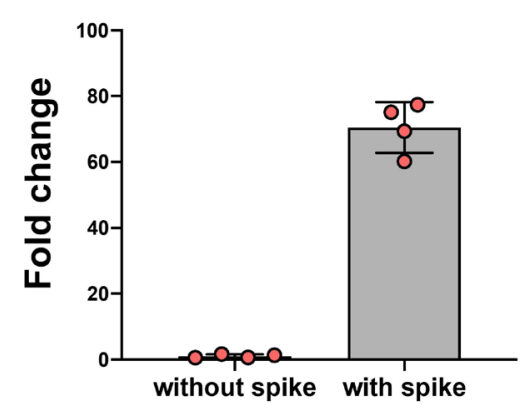

C

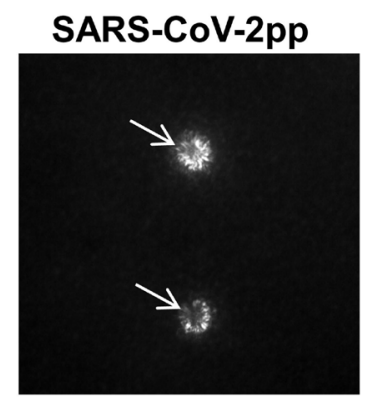

b
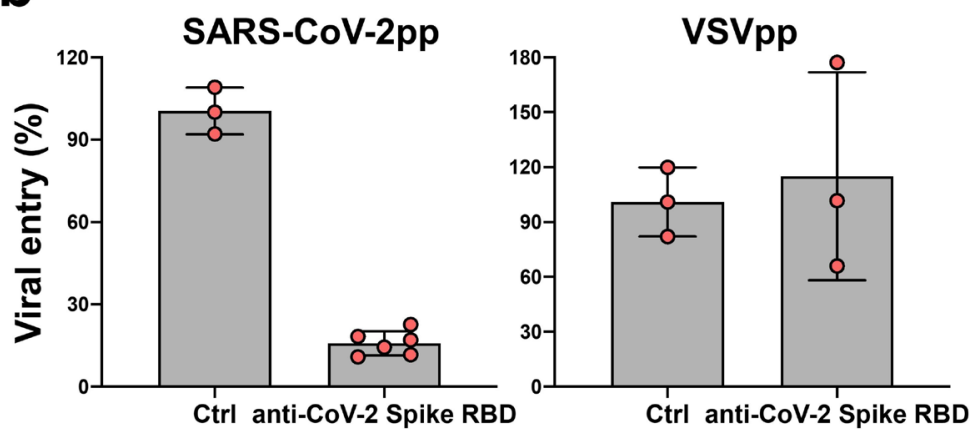

Merge

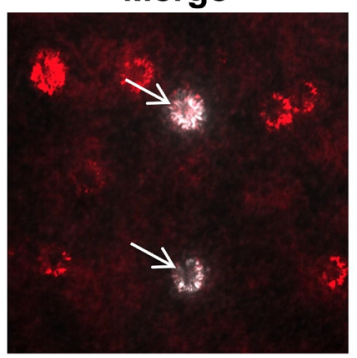
Airway Chips. (a) SARS-CoV-2 spike protein-mediated infection of CoV-2pp in human Airway Chips. Human Airway Chips were infected with SARS-CoV-2pp for 2 h, washed with PBS, and cultured for $48 \mathrm{~h}$. Cells were collected for detection of viral gene by RTqPCR. Data are expressed as fold change in viral gene expression relative to control pseudoparticles without SARS-CoV-2 spike protein.

(b) The infection of SARS-CoV-2pp was blocked by neutralizing antibody targeting the RBD of spike protein. SARS-CoV$2 \mathrm{pp}$ or VSVpp were incubated with neutralizing antibody for $1 \mathrm{~h}$ at room temperature before infecting human airway epithelium. $48 \mathrm{~h}$ later, cells were collected for detection of viral gene by RT-qPCR. PBS was used as control (Ctrl). (c) Immunofluorescence micrographs showing specific infection of SARS-CoV-2pp (white) in ciliated cells 


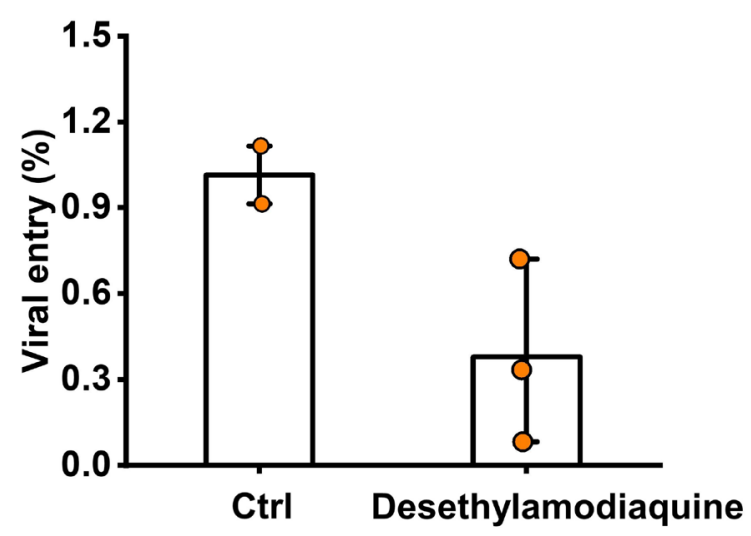

1098 CoV-2 viral entry in human Airway Chips. Desethylamodiaquine was delivered into

1099 apical and basal channels of the chip at its $C_{\max }$ in human blood $(1 \mu \mathrm{M})$, and one day

1100 later chips were infected with SARS-CoV-2pp while in the continued presence of the

1101 drugs for 2 days. The epithelium from the chips were collected for detection of viral

1102 gene by qRT-PCR; viral entry in untreated chips was set as $100 \%$. 


\section{Confidential}

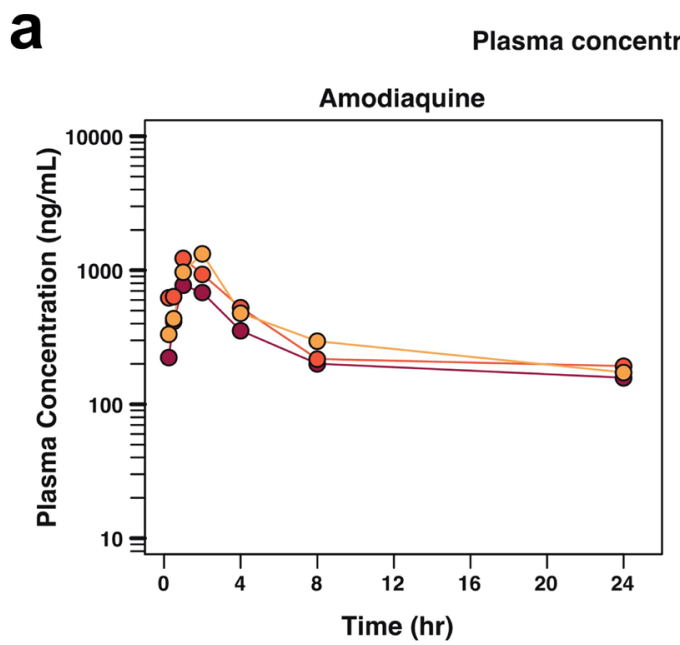

b

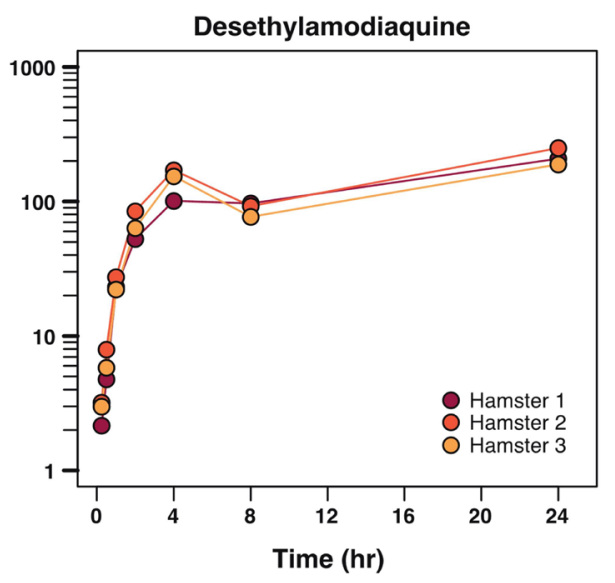

\begin{tabular}{|c|c|c|c|}
\hline PK parameters & Unit & Amodiaquine & Desethylamodiaquine \\
\hline $\mathrm{T}_{1 / 2}$ & $\mathrm{~h}$ & $18.1 \pm 2.9$ & $>24$ \\
\hline $\mathrm{T}_{\max }$ & $\mathrm{h}$ & $1.3 \pm 0.6$ & $24.0 \pm 0.0$ \\
\hline $\mathrm{C}_{\max }$ & $\mathrm{ng} / \mathrm{mL}(\mu \mathrm{M})$ & $1111 \pm 296(3.2 \pm 0.8)$ & $216 \pm 31(0.7 \pm 0.1)$ \\
\hline$A U C_{\text {last }}$ & $h^{*} n g / m L$ & $7644 \pm 1338$ & $3161 \pm 381$ \\
\hline Tissue & \multicolumn{2}{|c|}{ Amodiaquine $(\mu \mathrm{M})$} & thylamodiaquine $(\mu \mathrm{M})$ \\
\hline Lung & \multicolumn{2}{|c|}{$69.1 \pm 46.6$} & $31.5 \pm 16.8$ \\
\hline Kidney & \multicolumn{2}{|c|}{$20.6 \pm 8.4$} & $14.2 \pm 4.9$ \\
\hline Intestine & \multicolumn{2}{|c|}{$10.6 \pm 1.2$} & $5.4 \pm 0.8$ \\
\hline Heart & \multicolumn{2}{|c|}{$4.4 \pm 0.7$} & $2.8 \pm 0.3$ \\
\hline Plasma & \multicolumn{2}{|c|}{$0.5 \pm 0.05$} & $0.7 \pm 0.1$ \\
\hline
\end{tabular}

Extended Data Fig. 9. PK profiles for amodiaquine and desethylamodiaquine in

1105 hamsters. (a) Plasma concentration-time profiles showing mean concentration ( \pm s.d.)

1106 of amodiaquine (left) and desethylamodiaquine (right) at different time points after a

1107 single subcutaneous injection of amodiaquine (50 mg/kg). (b) PK parameters for

1108 amodiaquine and desethylamodiaquine in plasma based on results shown in (a). (c)

1109 Concentration of amodiaquine and desethylamodiaquine in tissues (lung, kidney,

1110 intestine, heart) and plasma 24 hours after subcutaneous dosing of $50 \mathrm{mg} / \mathrm{kg}$

1111 amodiaquine. 


\section{Supplementary Materials for}

\section{Human organ chip-enabled pipeline to rapidly repurpose therapeutics}

\section{during viral pandemics}

Longlong $\mathrm{Si}^{1 \#}$, Haiqing Bai ${ }^{1 \#, ~ M e l i s s a ~ R o d a s ~}{ }^{1}$, Wuji Cao ${ }^{1}$, Crystal Yuri Oh${ }^{1}$, Amanda Jiang ${ }^{3}$, Rasmus Moller ${ }^{4}$, Daisy Hoagland ${ }^{4}$, Kohei Oishi ${ }^{4}$, Shu Horiuchi ${ }^{4}$, Skyler Uhl ${ }^{4}$, Daniel BlancoMelo ${ }^{4}$, Randy A. Albrecht ${ }^{4,5}$, Wen-Chun Liü ${ }^{4,5}$, Tristan Jordan ${ }^{4}$, Benjamin E. Nilsson-Payant ${ }^{4}$, James Logue ${ }^{6}$, Robert Haupt ${ }^{6}$, Marisa McGrath ${ }^{6}$, Stuart Weston ${ }^{6}$, Atiq Nurani ${ }^{1}$, Seong Min Kim ${ }^{1}$, Danni Y. Zhu' ${ }^{1}$ Kambez H. Benam ${ }^{1,+}$, Girija Goyal ${ }^{1}$, Sarah E. Gilpin ${ }^{1}$, Rachelle Prantil-Baun ${ }^{1}$, Rani K. Powers ${ }^{1}$, Kenneth Carlson ${ }^{1}$, Matthew Frieman ${ }^{6}$, Benjamin R. tenOever ${ }^{4}$, and Donald E. Ingber ${ }^{1-3^{*}}$

${ }^{1}$ Wyss Institute for Biologically Inspired Engineering, Harvard University, Boston, MA 02115 , USA.

${ }^{2}$ Harvard John A. Paulson School of Engineering and Applied Sciences, Cambridge, MA 02139, USA.

${ }^{3}$ Vascular Biology Program and Department of Surgery, Boston Children's Hospital and Harvard Medical School, Boston, MA 02115, USA.

${ }^{4}$ Department of Microbiology, Icahn School of Medicine at Mount Sinai, New York, NY, USA.

${ }^{5}$ Global Health and Emerging Pathogens Institute, Icahn School of Medicine at Mount Sinai, New York, NY, USA.

${ }^{6}$ Department of Microbiology and Immunology, University of Maryland School of Medicine, Baltimore, MD 21201, USA

${ }^{+}$Current address: Division of Pulmonary Sciences and Critical Care Medicine, Departments of Medicine \& Bioengineering, U. of Colorado, Aurora, CO, USA. 


\section{LIMITATIONS}

Minimal viral replication without the addition of exogenous proteases

Cell lines Cannot be used for analysis of virus tropism

(A549, MDCK) Lack host immune, tissue-level, or organ-level responses

Do not mimic the in vivo phenotype of human lung cells and tissues

\begin{tabular}{ll}
\hline Short viability (4-10 days) & Limited availability of resources and expensive \\
human lung tissue & Poor reproducibility of experimental results \\
& Difficult to analyze mechanism of infection or host responses \\
& Not possible to study viral evolution \\
\hline Lack of physiologically relevant organ-level microenvironment \\
Difficult to access apical surface of the epithelium \\
Lack of air-liquid interface \\
Cannot study mucociliary clearance \\
Lacks endothelium and circulating immune cells \\
Absence of relevant mechanical cues (air flow, vascular flow) \\
Thick ECM gel complicates permeability and drug studies
\end{tabular}


Supplementary Table 2. Summary of antibodies used in this study

\begin{tabular}{|c|c|c|}
\hline Protein/Structure/Cell & Antibody & Vendor and Catalog \\
\hline Tight junction & Alexa Fluor 594 anti-ZO-1 & Life Technologies, Cat\# 339194 \\
\hline Cilia & $\begin{array}{l}\text { Alexa Fluor } 647 \text { anti-Acetyl-a- } \\
\text { Tubulin }\end{array}$ & Cell Signaling Technology, Cat\#81502 \\
\hline VE-Cadherin & FITC anti-human VE-cadherin & BD Biosciences, Cat\# 560411 \\
\hline Goblet cell & Anti-Mucin5AC & Santa Cruz Biotechnology, Cat\# sc-21701 \\
\hline Club cell & Anti-human Uteroglobin/cc-10 & R\&D Systems, Cat\# MAB4218SP \\
\hline Basal cell & Anti-Cytokeratin 5 & Sigma-Aldrich, Cat\# SAB5300265 \\
\hline Influenza NP & Anti-influenza NP & Invitrogen, Cat\# MA516291 \\
\hline hACE2 & Anti-hACE2 antibody & Abcam, cat. \#ab239924 \\
\hline ECM/Collagen & Anti-Collagen IV a1 & Novus Biologicals, Cat\# NBP1-97716G \\
\hline Neutrophil & $\begin{array}{l}\text { Alexa Fluor } 594 \text { anti-human } \\
\text { CD45 }\end{array}$ & Biolegend, Cat\# 368520 \\
\hline Influenza HA1 (H1N1) & $\begin{array}{l}\text { Rabbit anti-influenza A H1N1 } \\
\text { HA1 antibody }\end{array}$ & Sino Biological, Cat\# 11692-T62 \\
\hline Influenza HA (H3N2) & $\begin{array}{l}\text { Mouse monoclonal [AT1B7] to } \\
\text { Influenza A H3N2 HA antibody }\end{array}$ & Abcam, Cat\# ab139361 \\
\hline TMPRSS2 & Mouse anti-TMPRSS2 antibody & Novus Biologicals, Cat\# H00007113-B01P \\
\hline TMPRSS4 & Rabbit anti-TMPRSS4 antibody & Novus Biologicals, Cat\# NBP1-56991 \\
\hline TMPRSS11D & $\begin{array}{l}\text { Mouse anti-TMPRSS11D } \\
\text { antibody }\end{array}$ & Abnova, Cat\# H00009407-B01 \\
\hline TMPRSS11E & $\begin{array}{l}\text { Rabbit anti-TMPRSS11E } \\
\text { (DESC1) antibody }\end{array}$ & OriGene Technologies, Cat\# TA350522 \\
\hline \multirow{4}{*}{ Secondary antibody } & $\begin{array}{l}\text { Goat anti-mouse IgG, Alexa } \\
\text { Fluor } 488 / 594 / 647\end{array}$ & Life Technologies \\
\hline & $\begin{array}{l}\text { Goat anti-rabbit lgG, Alexa } \\
\text { Fluor } 488 / 594 / 647\end{array}$ & Life Technologies \\
\hline & Goat anti-rabbit IgG H\&L (HRP) & Abcam \\
\hline & $\begin{array}{l}\text { Goat anti-mouse IgG H\&L } \\
\text { (HRP) }\end{array}$ & Abcam \\
\hline
\end{tabular}


Supplementary Table 3. Primer sequences used for RT-qPCR analysis in this study.

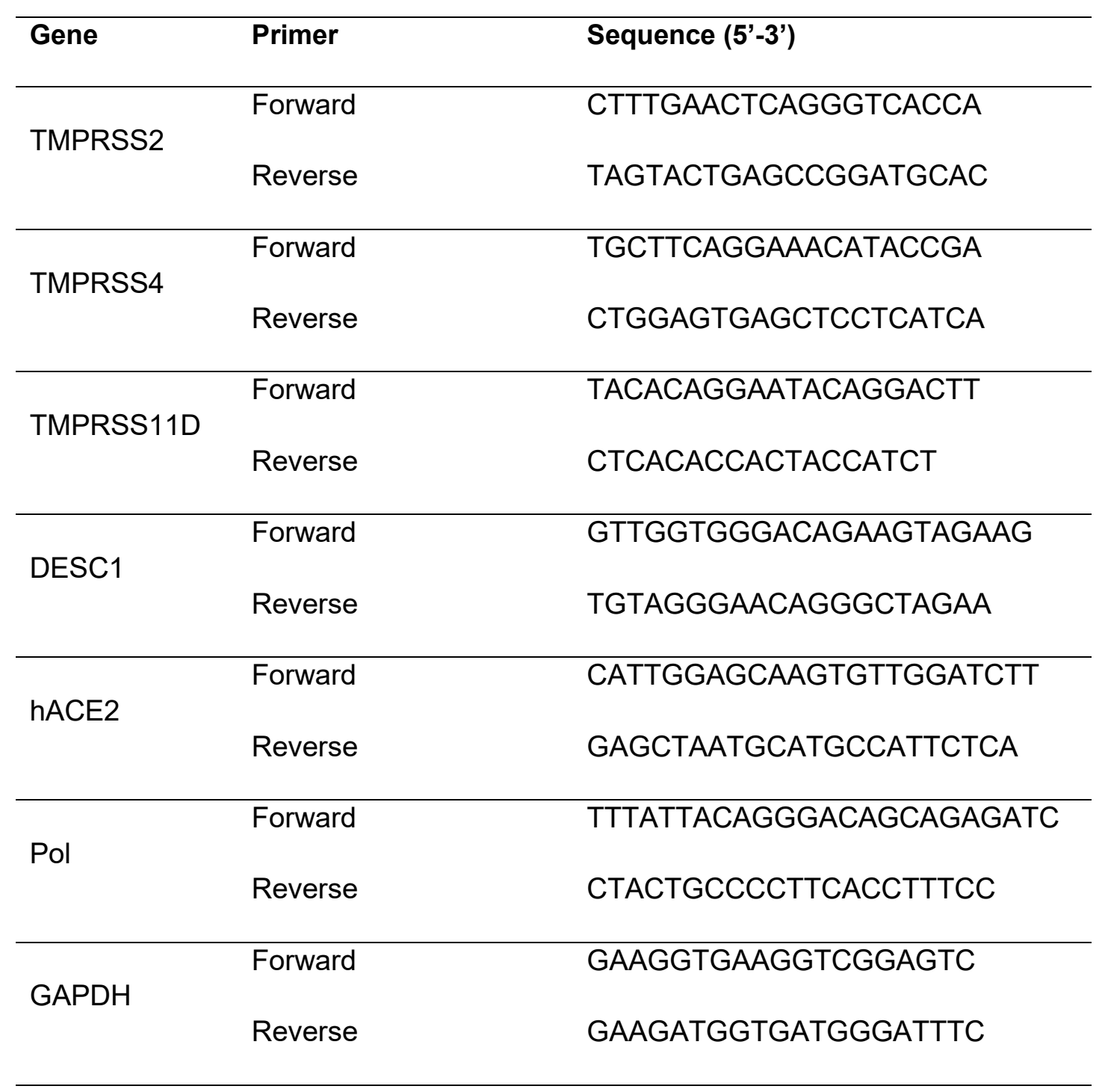


Other Supplementary Materials for this manuscript:

\section{Movie S1 (.mp4 format). Time-lapse video recording showing infection of the} human Airway Chip by GFP-labeled influenza PR8 (H1N1) virus recorded over 36 hours. The human Airway Chip was inoculated with GFP-labeled PR8 virus $(\mathrm{MOI}=0.01)$ and cultured for $36 \mathrm{~h}$ (images were recorded every $15 \mathrm{~min}$ ). Virus infection is indicated by the progressive increase in GFP-positive cells (movies are played at 18,000 times real time). (a) GFP signal, (b) merge of GFP and bright field.

\section{Movie S2 (.mp4 format). Real-time imaging showing recruitment of human} neutrophils to endothelium under flow in the human Airway Chip infected with influenza virus. (a) The movie shows fluorescently-labelled human neutrophils flowing over a quiescent endothelium within the control Airway Chip that contains an airway epithelium on the opposite side of the porous membrane from the endothelium. Note that the neutrophils flow by and do not stick to the inactivated endothelium under these control conditions, as observed in normal vessels in vivo. (b) In contrast, many of the flowing neutrophils adhere to the surface of the activated endothelium within an Airway Chip that has been infected with influenza H1N1 virus $(\mathrm{MOI}=0.1)$ via its introduction into the upper air channel, much as they do at sites of inflammation in vivo. The movies are played at 25 times real time. 